\title{
The impacts of digital finance development on household income, consumption, and financial asset holding: an extreme value analysis of China's microdata
}

\author{
Hang Lin ${ }^{1,2} \cdot$ Zhengjun Zhang ${ }^{2}$ \\ Received: 31 May 2021 / Accepted: 19 January 2022 \\ ○ The Author(s), under exclusive licence to Springer-Verlag London Ltd., part of Springer Nature 2022
}

\begin{abstract}
This paper examines the roles of digital finance development in household income, consumption, and financial asset holding from an extreme value theory perspective. Three types of extreme pairs (Min to Min, Max to Max, and Max to Min) are constructed, corresponding to the three aspects of the economic welfare of digital finance: fairness, efficiency, and their trade-off. Using panel data from the Peking University Digital Financial Inclusion Index of China (PKU-DFIIC) and China Family Panel Studies (CFPS) over time span 2014-2018, this paper models the block maxima and minima of variables by fitting them with generalized extreme value (GEV) distribution. The binary expansion testing (BET) is used to detect the nonlinear dependence between digital finance and household economic variables. The tail quotient correlation coefficient (TQCC) is used to quantify the tail dependencies. The results show that: (1) digital finance has significant fairness effects in reducing poverty, increasing consumption, and promoting financial asset holding; (2) digital finance shows effects of promoting incentives and efficiency in household income and financial asset holding, but this effect is relatively limited in household consumption; (3) digital finance generally increases efficiency without harming fairness in terms of all cases of household income and consumption, and most of the cases regarding household financial asset holding; (4) the positive spatial externality of digital finance exists for all household economic variables; and, for pairs regarding household income and consumption, the wider the scope, the greater the spatial spillover effect. The result of this paper implies many novel policy implications.
\end{abstract}

Keywords Digital finance $\cdot$ Household income $\cdot$ Household consumption $\cdot$ Household financial asset holding $\cdot$ Extreme value theory $\cdot$ Tail dependence

\section{Introduction}

In recent years, with the in-depth integration of internet technology and finance, the digital financial activity supported by new information technology is becoming an indispensable part of the financial system and the whole business cycle. Digital finance, also termed fintech or internet finance,

Hang Lin

Zhengjun Zhang

zjz@stat.wisc.edu

1 School of Statistics, University of International Business and Economics, 10 Huixin East Street, Chaoyang District, Beijing 100029, China

2 Department of Statistics, University of Wisconsin - Madison, 1300 University Ave, Madison, WI 53706, USA changes people's daily lives and impacts many aspects of household economic and financial activities [4]. Digital finance can lead to greater financial inclusion and extend financial services to non-financial sectors, thereby providing individuals with many daily services [7]. Because digital finance does not require banks to serve as an intermediary between lenders and borrowers, it can decrease the degree of information asymmetry and reduce transaction costs, which dramatically improves the efficiency of the economy [1, 23]. In September 2016, the "G20 Advanced Principles of Digital Inclusive Finance" was passed in Hangzhou, China, aiming to promote the integrated development of inclusive finance and digital technology. This agreement indicates that "inclusiveness" will be regarded as an important connotation of digital finance in the future. While digital finance improves economic efficiency, its impacts on social fairness and equality are worth emphasizing as well [10]. As the 
foothold of "inclusiveness," household welfare and related economic variables (such as household income, consumption, and financial asset holding) naturally become important concerns for the economic effects of digital finance.

In the literature, many studies have discussed the poverty reduction effect of digital finance by investigating its impact on household income. Ozili [24] analyzed the impact of digital finance and inclusive finance on users of financial services and found that digital financial services are an effective way to reduce poverty in developing countries. Using the panel data of 31 provinces in China from 2011 to 2017, Appiah-Otoo and Song [4] found that fintech complements economic growth and financial development to reduce poverty in China. For a cross-country study regarding poverty, a panel of 140 countries using the Global Findex waves of survey data for 2011, 2014, and 2017, Demir et al. [10] invoked quantile regression analysis and found that while financial inclusion significantly reduces inequality at all quantiles of the inequality distribution, these effects are primarily associated with higher-income countries. Regarding the income gap between urban and rural areas, Zhang et al. [36] found that digital finance development is positively correlated with household income, and the positive effect is larger for rural households than the urban counterpart, suggesting that digital finance may narrow the urban-rural income gap.

In terms of household consumption, Yi and Zhou [30] discussed the impact of digital finance in promoting household consumption based on microdata of Chinese households and evidenced that there is a significant relationship between household consumption and digital finance development in rural areas, central and western regions, and low- and middle-income families. Similar empirical results can also be found in Zhao [31] and Kang [18]. Based on the 2015 China Household Finance Survey data, Song et al. [29] compared digital finance and traditional finance on the role of consumption promotion and outlined that both access to formal finance and digital finance significantly promote households' consumption. Meanwhile, these effects are much larger for rural households and poorer households in China. For the effect of digital finance during the COVID-19 period, Liu et al. [22] employed the China Household Finance Survey (CHFS) data and found that there was a significant decline in household consumption during the outbreak period. Based on previous studies, Li et al. [20] refined the mechanism from digital finance to household consumption using heterogeneity analysis, and the results showed that households with fewer assets, lower income, less financial literacy, and in third- and fourth-tier cities experienced larger facilitating effects of digital finance on consumption compared to their counterparts.

The influence of digital finance on household financial asset holding and the relationship between digital finance and traditional finance are also hot topics in the literature.
Radcliffe and Voorhies [26] theoretically described how the cash-digital divide creates stark inequities in the financial lives of poor households and believed that digital financial services lubricate economic activities, make financial products and services cheaper, and increase the actual financial asset holdings of "poor" households. Based on balanced panel data from the China Family Panel Studies (CFPS) and the Digital Inclusive Financial Index developed by Peking University, using the OLS and two-way fixed-effect models, Huang [17] found that the development of digital finance could significantly increase household leverage rate. Using administrative and survey data, Bharadwaj et al. [6] examined the take-up and impacts of M-Shwari in Kenya and found that while digital loans did improve financial access and resilience, they were not a panacea for greater credit market failures. Using a quantitative dynamic general equilibrium model at the macro-finance level and based on firm-level data from Kenya, Beck et al. [5] found that digital payments significantly improved entrepreneurial growth and macroeconomic development.

While the existing studies do lay the foundation and offer important inspiration for our topic, it is shown that there are still many gaps in related fields. First, from the perspective of methodology, most of the existing studies are based on totals and averages, and the literature focusing on the tail effects of digital finance on household financial activities is scarce. Second, from the perspective of economic welfare, most previous studies involve the economic efficiency of digital finance, but very few of them have paid attention to the effect of fairness (for example, the relationship between "worst" digital finance development and the "poorest" household, the lowest consumption, and the minimal financial asset holding). ${ }^{1}$ Third, from the perspective of property rights and externalities, there are very few existing studies that take into account the externalities of digital finance to household economic activities, especially its spatial spillover effect.

This paper tries to fill the current gaps by introducing the following three novelties. First, at the methodology level, extreme value theory and nonlinear dependence testing are used in this paper to detect nonlinear dependencies

\footnotetext{
1 In welfare economics, it is hard to define what fairness is [12]. Empirically, researchers typically convert the connotation of "fairness" into that of "inequality" so that one can measure it using statistics that measure the degree of dispersion, such as the variance of income, consumption, or other economic variables [2]. In this paper, we directly focus on the very nature of "fairness": people's "worst" situation. Under such definition, when claiming certain treatment can make the economic system fairer, people with the worst living situation get better than before, no matter how the gap between the rich and poor changes. In addition, according to Rawls [27], "fairness" includes two connotations: fair opportunity and fair result. In this sense, this paper mainly focuses on the latter
} 
and quantify tail dependencies between digital finance and household economic variables. Second, this paper investigates the economic welfares of digital finance at the economic level in terms of two different connotations in economics: efficiency and fairness. Consequently, pairs used to characterize efficiency (Max to Max), fairness (Min to Min), as well their relationship (Max to Min) are constructed using extreme value theory (see "Section 2.2" for details). It is noteworthy that this paper, by constructing Max to Min pair, can answer the question "whether digital finance increases efficiency while harming fairness," which is very rare in the literature. Third, this paper considers digital finance's spatial externality at the property rights and externalities levels. The block maxima method (BMM) is used to construct research variables so that the spatial spillover effect of each digital finance variable can be implied in our result as a byproduct.

There are three sub-research questions of our study. First, to investigate the fairness issue. That is, to figure out the impact of the "worst" digital finance development on the "worst" household income/consumption/financial asset holding. Second, to study the "efficiency" issue. That is, to examine the effect of the "best" digital finance development on the "best" household income/consumption/financial asset holding. Third, to investigate the relationship or trade-off between fairness and efficiency. This is a question regarding the cost of fairness for economic efficiency. That is, to study the impact of the "best" digital finance development on the "worst" household income/consumption/financial asset holding.

Three extreme pairs (Min to Min, Max to Max, and Max to Min) are constructed between each digital finance variable and household economic variable to answer the above three questions. Generalized extreme value (GEV) is used to fit the marginal distribution of each variable, and binary expansion statistics (BEStat) and binary expansion testing (BET, [34] are utilized to detect whether or not there exists nonlinear dependence between digital finance variables and household economic variables. Finally, this paper draws conclusions using the tail quotient correlation coefficient (TQCC, [32, 33]), a tail dependence measure. The result of this paper implies important implications for policymakers.

The rest of the paper is organized as follows. "Section 2" introduces the variables and data utilized in this study and how three extreme pairs between digital finance and household economic variables are constructed. The extreme value methodologies used in this paper are explained in "Section 3." "Section 4" reports the empirical results. "Section 5" concludes the paper, offers policy implications based on the empirical findings, and discusses further research directions in the future.

\section{Data, variables, and pair construction}

\subsection{Data and variables}

This study adopts two categories of data: (1) the regional data of digital finance indexes from Peking University Digital Financial Inclusion Index of China (PKU-DFIIC) and (2) the microdata of household economic variables from China Family Panel Studies (CFPS).

The digital finance data used in this paper is the digital inclusive finance index system developed by Peking University to reflect the development of digital finance [16]. There are one aggregate index (index aggregate) and three sub-indexes (coverage breadth, usage depth, and digitization level) in this digital financial services index system. There are three scope levels data for the aggregate index and each sub-index: provincial level, city-level, and county-level. ${ }^{2}$ The original data utilized in this paper for pair construction is the county-level data. Using the BMM method, each digital financial variable is the city or provincial maximum or minimum over counties (see "Section 2.2" for pair construction). After excluding some missing data and observations, there are 11,862 effective county-level observations over the whole time span (2014-2018), where 1,752 obs, 1,731 obs, 2,791 obs, 2,786 obs, and 2,802 obs in 2014, 2015, 2016, 2017 , and 2018, respectively.

The household data used in this paper is the microdata from China Family Panel Studies (CFPS), which aims to collect data at three levels of individuals, families, and communities to reflect the changes in China's society, economy, population, education, and health. For the research purpose of this paper, we select three variables from this dataset: per capita income, consumption, and financial asset holding. After excluding some missing data and observations, there are 41,643 effective observations on household economic activities in total, and there are 13,406 obs, 14,019 obs, and 14,281 obs in 2014,2016 , and 2018, respectively. For the convenience of illustration, all variables are adjusted to millions of RMB units.

This paper uses four digital finance variables (one aggregate index and three sub-indexes) and three household economic variables (income, consumption, and financial asset holding) for extreme pair construction. After being matched as a pair, all variables will be converted to city-level or provincial-level data.

\subsection{Pair construction}

To study the tail dependence between digital financial variables and household economic variables, this paper firstly

$\overline{2}$ The county-level data is only available since 2014 . 
Table 1 The extreme pair construction description

\begin{tabular}{|c|c|c|c|}
\hline Pair & Scope & Lag & Economic explanation \\
\hline \multirow[t]{4}{*}{ Min to Min } & \multirow[t]{2}{*}{ City } & No & The contemporaneous effect for fairness at the city-level \\
\hline & & Yes & The intertemporal effect for fairness at the city-level \\
\hline & \multirow[t]{2}{*}{ Province } & No & The contemporaneous effect for fairness at the provincial level \\
\hline & & Yes & The intertemporal effect for fairness at the provincial level \\
\hline \multirow[t]{4}{*}{ Max to Max } & \multirow[t]{2}{*}{ City } & No & The contemporaneous effect for efficiency at the city-level \\
\hline & & Yes & The intertemporal effect for efficiency at the city-level \\
\hline & \multirow[t]{2}{*}{ Province } & No & The contemporaneous effect for efficiency at the provincial level \\
\hline & & Yes & The intertemporal effect for efficiency at the provincial level \\
\hline \multirow[t]{4}{*}{ Max to Min } & \multirow[t]{2}{*}{ City } & No & The contemporaneous fairness cost of achieving efficiency at the city-level \\
\hline & & Yes & The intertemporal fairness cost of achieving efficiency at the city-level \\
\hline & \multirow[t]{2}{*}{ Province } & No & The contemporaneous fairness cost of achieving efficiency at the provincial level \\
\hline & & Yes & The intertemporal fairness cost of achieving efficiency at the provincial level \\
\hline
\end{tabular}

utilizes the block maxima method (BMM) in extreme value theory to construct extreme pairs. According to the idea of BMM, the formation of city-level and provincial-level administrative divisions are naturally "blocks" for their subregions (e.g., the county-level administrative units). Therefore, we use city or province as blocks for each variable in this paper and take maxima and minima over each variable. Based on these extreme values (the block maxima and minima), we propose the following pair system, including three extreme pairs.

First, we study Min to Min pair (or Min to Min dimension). This pair is composed of the block minima of the digital finance variable and the block minima of the household economic variable. Intuitively, this pair is used to describe the relationship between the "worst" digital finance development level and the "worst" household economic level, which corresponds to the connotation of "fairness" in economics.

Second, the Max to Max pair (or Max to Max dimension). This pair is composed of the block maxima of the digital finance variable and the block maxima of the household economic variable. This pair is used to describe the relationship between the "best" digital finance development level and the "best" household economic level, which corresponds to the connotation of "efficiency" and "incentive" in economics.

Third, the Max to Min pair (or Max to Min dimension). This pair is composed of the block maxima of the digital finance variable and the block minima of the household economic variable. This pair describes whether the improvement in the upper bound of digital finance harms the "worst" household's economic situation. This pair corresponds to the relationship or the trade-off between efficiency and fairness in economics.

Regarding the above three pairs, motivated by the permanent income hypothesis [13] and existing empirical researches [20, 30, 37], illustrate the intertemporal effects of digital finance is very important and cannot be ignored.
To illustrate the intertemporal effect, this paper takes the first-order lag in time for the digital financial variables in each pair to generate a (new) lagged pair. In other words, each lagging pair is composed of the digital finance variable in the previous period and the household economic variable in the current period (e.g., the 2015 digital finance variable to the 2016 household economic variable in the 2016 lagging pair).

All the constructed extreme pairs are listed in Table 1, together with corresponding economic meanings.

\section{Methodology}

There are three steps of the modeling procedure of this paper: (1) fit the maxima and/or minima of variables with generalized extreme value (GEV) distribution; (2) use binary expansion statistics (BEStat) and binary expansion testing (BET) to detect whether or not there exist nonlinear dependencies between digital finance variables and household economic variables; and then (3) the tail quotient correlation coefficient (TQCC) is used to quantify tail dependencies of variables. Synthesizing the above procedure, we referred to the research methodology in this paper as the GEV-BETTQCC method. ${ }^{3}$

\footnotetext{
${ }^{3}$ In fact, we also studied the dependent structure of each pair in this paper using Gumbel copula. Since Gumbel copula is eventually fail to capture the tail dependence of some of the variables (one of the possible reasons can be that the parameters used to calculate the upper tail dependence need to be estimated using full sample), in order to avoid misleading readers, we omitted these results. Those in need can contact the author to obtain the results.
} 


\subsection{Specification for marginal distributions}

This paper uses BMM for extreme pair construction (see "Section 2.2"). It is natural to use the generalized extreme value $(\mathrm{GEV})$ distribution to fit the constructed pairs and investigate their basic tail behaviors by examining their shape parameters.

According to Fisher and Tippett [11], Gnedenko [14], and Gumbel [15], we present the following Theorem 1 without showing the proof which can be seen in the literature.

Theorem 1 If there exist sequences of constants $\left\{a_{n}>0\right\}$ and $\left\{b_{n}\right\}$ such that

$\operatorname{Pr}\left\{\frac{M_{n}-b_{n}}{a_{n}} \leq z\right\} \rightarrow G(z)$,

as $n \rightarrow \infty$ for a non-degenerate distribution function $G$, then $G$ is a member of the GEV family

$G(z)=\exp \left\{-\left[1+\xi\left(\frac{z-\mu}{\sigma}\right)\right]^{-\frac{1}{\xi}}\right\}$,

which is defined on $\{z: 1+\xi(z-\mu) / \sigma>0\}$, where $-\infty<\mu<\infty, \sigma>0$, and $-\infty<\xi<\infty$.

Furthermore, the GEV distribution includes three types, corresponding to different shapes of their tails:

Type I GEV: Gumbel distribution,

$G(z)=\exp \left\{\exp \left[-\left(\frac{z-b}{a}\right)\right\},-\infty<z<\infty, \mathrm{a}>0,-\infty<b<\infty ;\right.$

Type II GEV: Fréchet distribution,

$G(z)=\exp \left\{-\left(\frac{z-b}{a}\right)^{-\alpha}\right\}, z>b, \mathrm{a}>0, \alpha>0,-\infty<b<\infty ;$

Type III GEV: Weibull distribution,

$G(z)=\exp \left\{-\left(-\frac{z-b}{a}\right)^{\alpha}\right\}, z<b, \mathrm{a}>0, \alpha>0,-\infty<b<\infty ;$

where $\alpha=1 / \xi$.

The GEV parameters are estimated using maximum loglikelihood estimation (MLE) in this paper.

Regarding the block minima, we change the signs of them, and then, according to Theorem 1, they are converted to block maxima and thus can be modeled by GEV for maxima using Eq. (1). For more details about the GEV distribution for minima and its connection with GEV distribution for maxima, one can refer to Coles et al. [8].

In this paper, since the spatial block maxima (or minima) of each variable within a block (city or province) may not come from the same sub-region (county), the illustration of spatial externality is, therefore, a natural byproduct by using BMM-GEV estimations. The spatial spillover effect can be further examined using the TQCC method introduced in "Section 3.3," and serves as one of the novelties of this paper.

It is worth noting that by forming block maxima and minima for variables and utilizing extreme value theory, the "endogeneity" issue which is typically concerned in traditional applied microeconomic literature, can be more or less alleviated. First, an extreme pair may be independent of the "fixed effect" at each region because the highest (or lowest) level of digital finance and the highest (or lowest) level of household economic activity may not belong to the same sub-region. Second, to address the "endogeneity" due to "interactive causality," one may examine the reverse intertemporal effects using TQCC. If the reverse tail dependencies are generally not significant, this effect can be ruled out (see "Section 4.3" and Appendix for details). Third, the "endogeneity" may also be alleviated by the data structure of this study. The digital financial inclusion data used in this study are regional. According to $\mathrm{Li}$ and $\mathrm{Wu}$ [21], the development of regional digital finance is exogenous to urban residents, and thus, endogenous problems can be overcome to a certain extent.

\subsection{Testing for non-linear dependence}

In this paper, we utilize the framework of binary expansion statistics (BEStat) and binary expansion testing (BET) proposed by Zhang [34] for nonlinear dependence detection. The foundation for BEStat is the following theorem regarding the binary expansion of a uniform random variable [19].

Theorem 2 If $U \sim$ Uniform $[0,1]$, then $U=\sum_{k=1}^{\infty} \frac{A_{k}}{2^{k}}$ where

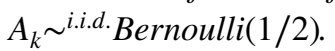

The binary expansion in Theorem 2 is used to decompose the information about $U$ into information from independent Bernoulli $A_{k}$ 's, which can be seen as indicator functions of $U$. To consider the (in)dependent problem of variable $U$ and $V$, one can truncate the above binary expansions of $U$ and $V$ at some finite depths $d_{1}$ and $d_{2}$, respectively. That is, $U\left(d_{1}\right)=\sum_{k=1}^{d_{1}} \frac{A_{k}}{2^{k}}$ and $V\left(d_{2}\right)=\sum_{k=1}^{d_{2}} \frac{B_{k}}{2^{k}}$. It can be shown that this approach has universality, identifiability, and uniformity [34]. Then, Zhang [34] defined BEStat and BET as follows.

Definition 1 Statistics of functions of finitely many Bernoulli variables from marginal binary expansions is called the binary expansion statistics (BEStat).

Definition 2 The testing framework based on the binary expansion filtration approximation to a certain depth is called the binary expansion testing (BET). 
Formally, denote the bivariate uniform distribution over $\left\{\frac{0}{2^{d_{1}}}, \cdot, \frac{2^{d_{1}}-1}{2^{d_{1}}}\right\} \times\left\{\frac{0}{2^{d_{1}}}, \cdot, \frac{2^{d_{1}}-1}{2^{d_{1}}}\right\}$ by $\mathbf{P}_{0, d_{1}, d_{2}}$. For some $0<\delta \leq 1$, consider

$H_{0, d_{1}, d_{2}}: \mathbf{P}_{\left(U_{d_{1}}, V_{d_{2}}\right)}=\mathbf{P}_{0, d_{1}, d_{2}}$

VS.

$H_{1, d_{1}, d_{2}}: T V\left(\mathbf{P}_{\left(U_{d_{1}}, V_{d_{2}}\right)}, \mathbf{P}_{0, d_{1}, d_{2}}\right) \geq \delta$

where $\mathbf{P}$ means the joint distribution, and $T V$ stands for the total variation distance measuring by $T V(\mathbf{P}, \mathbf{Q})=\sup _{S \in \mathbb{F}}|\mathbf{P}(S)-\mathbf{Q}(S)|$.

Not rejecting the null hypothesis in the BET at depths $\left(d_{1}, d_{2}\right)$ indicates that there is no strong evidence against the null hypothesis of independence between $U$ and $V$ up to depths $d_{1}$ and $d_{2}$ in the binary expansions. In this paper, the BETs are conducted at $d=1,2,3,4$, where $d_{1}=d_{2}=d$.

\subsection{Tail dependence measure}

In this paper, we use the tail quotient correlation coefficient (TQCC), proposed by Zhang [32], and further theoretically studied in Zhang et al. [33], to measure the tail dependences between digital finance and household economic variables. The TQCC is defined as:

Definition 3 If $\left\{\left(X_{i}, Y_{i}\right)\right\}_{i=1}^{n}$ is a random sample of random variables being tail equivalent to unit Fréchet random variables $(X, Y)$,

$q_{u_{n}}=\frac{\max _{1 \leq i \leq n} \frac{\max \left(X_{i}, u_{n}\right)}{\max \left(Y_{i}, u_{n}\right)}+\max _{1 \leq i \leq n} \frac{\max \left(Y_{i}, u_{n}\right)}{\max \left(X_{i}, u_{n}\right)}-2}{\max _{1 \leq i \leq n} \frac{\max \left(X_{i}, u_{n}\right)}{\max \left(Y_{i}, u_{n}\right)} \times \max _{1 \leq i \leq n} \frac{\max \left(Y_{i}, u_{n}\right)}{\max \left(X_{i}, u_{n}\right)}-1}$,

is the tail quotient correlation coefficient (TQCC) where $u_{n}$ is the varying threshold that tend to infinity.

Specifically, one can set

$u_{n}=\min \left(X_{u q}, Y_{u q}\right)$

where $u q$ is a quantile level, and $X_{u q}$ and $Y_{u q}$ are upper$u q$ quantiles of $X$ and $Y$, respectively. In this paper, $u q$ is selected to be 0.90 and 0.95 without loss of generality.

If the marginal distribution of each variable is GEV distribution, based on the fitting results from "Section 3.1," the TQCC can be directly obtained by plugging in GEV C.D.F. into the following equation via the following theorem.

Theorem 3 Let $\left\{\left(X_{i}, Y_{i}\right)\right\}_{i=1}^{n}$ be a sample of $T 1$ type tail independent random variables $(X, Y)$ whose marginal domains of attraction are GEV random variables with parameters $\theta_{X} a n d \theta_{Y}$, respectively. Under certain conditions, if $\widehat{X}_{i}=-1 / \log \left\{H\left(X_{i} ; \widehat{\theta}_{X}\right)\right\}$, and $\widehat{Y}_{i}=-1 / \log \left\{H\left(Y_{i} ; \widehat{\theta}_{Y}\right)\right\}$ , where $\widehat{\theta}_{X}$ and $\hat{\theta}_{Y}$ are estimated GEV parameters for $X$ and $Y$ respectively, andHis the GEV C.D.F., the TQCC with estimated GEV parameters can be written as.

$q_{u_{n}}=\frac{\max _{1 \leq i \leq n} \frac{\max \left(\hat{X}_{i}, u_{n}\right)}{\max \left(\hat{Y}_{i}, u_{n}\right)}+\max _{1 \leq i \leq n} \frac{\max \left(\hat{Y}_{i}, u_{n}\right)}{\max \left(\hat{X}_{i}, u_{n}\right)}-2}{\max _{1 \leq i \leq n} \frac{\max \left(\hat{X}_{i}, u_{n}\right)}{\max \left(\hat{Y}_{i}, u_{n}\right)} \times \max _{1 \leq i \leq n} \frac{\max \left(\hat{Y}_{i}, u_{n}\right)}{\max \left(\hat{X}_{i}, u_{n}\right)}-1}$

It can be proved that Eq. (5) and Eq. (4) are equivalent.

Based on the computed TQCC, one can formulate the following hypothesis test of independence, and test tail (in) dependence among variables by using a gamma test proposed by Zhang [32]:

$H_{0}^{c}: X$ and $Y$ are tail independent.

$H_{1}^{c}: X$ and $Y$ are tail dependent.

Here the superscript $c$ means that the complete data are used for this test. Under $H_{0}^{c}$, we have the following theorem [32]:

Theorem 4 If $X$ and $Y$ are tail independent and have unit Fréchet margins, and $\left(X_{i}, Y_{i}\right), i=1,2, \cdots, n$ is a random sample from $(X, Y)$, then random variables $\max _{i \leq n}\left(Y_{i} / X_{i}\right)$ and $\min _{i \leq n}\left(Y_{i} / X_{i}\right)$ are asymptotically independent. Furthermore, as $n \rightarrow \infty$, the random variable $q_{u_{n}}$ is asymptotically gamma distributed, that is,

$n q_{u_{n}} \stackrel{L}{\rightarrow} \Gamma$,

where $\Gamma$ is a gamma $(2,1)$ random variable.

This gamma test can be generalized to the chi-square test [33], which is consistent with the gamma test in terms of testing tail dependence using TQCC.

\section{Empirical results}

\subsection{The GEV fitting results}

We begin our empirical analysis by estimating each variable's block maxima and block minima using GEV distribution. Tables 2 and 3 provide the GEV estimation results of digital finance indexes and household economic variables, respectively. The standard error of each estimated parameter is in parentheses.

As shown in Table 2, all shape parameters of digital finance (sub-)indexes are negative, meaning that their block 
Table 2 The GEV estimations for digital finance variables

\begin{tabular}{|c|c|c|c|c|c|}
\hline & Variables & Scope & $\xi$ & $\sigma$ & $\mu$ \\
\hline \multirow[t]{8}{*}{ Block minima } & \multirow[t]{2}{*}{ Index aggregate } & City & $\begin{array}{l}-0.5483 \\
(0.0223)\end{array}$ & $\begin{array}{l}29.0602 \\
(1.1403)\end{array}$ & $\begin{array}{l}69.0777 \\
(1.5021)\end{array}$ \\
\hline & & Province & $\begin{array}{l}-0.6435 \\
(0.0675)\end{array}$ & $\begin{array}{l}32.0450 \\
(3.2004)\end{array}$ & $\begin{array}{l}63.1132 \\
(3.9493)\end{array}$ \\
\hline & \multirow[t]{2}{*}{ Coverage breadth } & City & $\begin{array}{l}-0.7219 \\
(0.000002)\end{array}$ & $\begin{array}{l}27.3877 \\
(0.9673)\end{array}$ & $\begin{array}{l}67.2023 \\
(1.3350)\end{array}$ \\
\hline & & Province & $\begin{array}{l}-0.9068 \\
(0.000002)\end{array}$ & $\begin{array}{l}31.0004 \\
(3.2502)\end{array}$ & $\begin{array}{l}60.3212 \\
(3.5806)\end{array}$ \\
\hline & \multirow[t]{2}{*}{ Usage depth } & City & $\begin{array}{l}-0.3418 \\
(0.0304)\end{array}$ & $\begin{array}{l}34.0697 \\
(1.3150)\end{array}$ & $\begin{array}{l}71.0644 \\
(1.8205)\end{array}$ \\
\hline & & Province & $\begin{array}{l}-0.4181 \\
(0.0717)\end{array}$ & $\begin{array}{l}37.2767 \\
(3.4637)\end{array}$ & $\begin{array}{l}62.4761 \\
(4.6944)\end{array}$ \\
\hline & \multirow[t]{2}{*}{ Digitization level } & City & $\begin{array}{l}-0.6602 \\
(0.0397)\end{array}$ & $\begin{array}{l}40.2930 \\
(1.9109)\end{array}$ & $\begin{array}{l}58.2295 \\
(2.1252)\end{array}$ \\
\hline & & Province & $\begin{array}{l}-0.4539 \\
(0.1588)\end{array}$ & $\begin{array}{l}37.8692 \\
(4.7722)\end{array}$ & $\begin{array}{l}41.2923 \\
(5.3942)\end{array}$ \\
\hline \multirow[t]{8}{*}{ Block Maxima } & \multirow[t]{2}{*}{ Index aggregate } & City & $\begin{array}{l}-0.4346 \\
(0.0181)\end{array}$ & $\begin{array}{l}27.6754 \\
(1.02512)\end{array}$ & $\begin{array}{l}84.2227 \\
(1.4313)\end{array}$ \\
\hline & & Province & $\begin{array}{l}-0.4153 \\
(0.0690)\end{array}$ & $\begin{array}{l}23.0983 \\
(2.1627)\end{array}$ & $\begin{array}{l}96.2954 \\
(2.8981)\end{array}$ \\
\hline & \multirow[t]{2}{*}{ Coverage breadth } & City & $\begin{array}{l}-0.6833 \\
(0.000002)\end{array}$ & $\begin{array}{l}20.3807 \\
(0.2024)\end{array}$ & $\begin{array}{l}89.8607 \\
(0.3028)\end{array}$ \\
\hline & & Province & $\begin{array}{l}-0.7195 \\
(0.0627)\end{array}$ & $\begin{array}{l}13.0881 \\
(1.2930)\end{array}$ & $\begin{array}{l}101.4309 \\
(1.6064)\end{array}$ \\
\hline & \multirow[t]{2}{*}{ Usage depth } & City & $\begin{array}{l}-0.2637 \\
(0.0348)\end{array}$ & $\begin{array}{l}34.2150 \\
(1.3624)\end{array}$ & $\begin{array}{l}91.9703 \\
(1.8584)\end{array}$ \\
\hline & & Province & $\begin{array}{l}-0.1437 \\
(0.1412)\end{array}$ & $\begin{array}{l}31.6940 \\
(3.5242)\end{array}$ & $\begin{array}{l}104.0663 \\
(4.5270)\end{array}$ \\
\hline & \multirow[t]{2}{*}{ Digitization level } & City & $\begin{array}{l}-0.4024 \\
(0.0200)\end{array}$ & $\begin{array}{l}31.1668 \\
(1.1630)\end{array}$ & $\begin{array}{l}79.4952 \\
(1.6189)\end{array}$ \\
\hline & & Province & $\begin{array}{l}-0.4466 \\
(0.0750)\end{array}$ & $\begin{array}{l}27.9663 \\
(2.6144)\end{array}$ & $\begin{array}{l}100.3493 \\
(3.5210)\end{array}$ \\
\hline
\end{tabular}

maxima and minima follow the type III GEV (Weibull) distribution. This implies that there are upper limits for these indexes in our sample period, and can be intuitively explained as follows. As a high-tech-based industry, the development of digital finance is bounded by technological advances within a certain period of time. Since the technological level is relatively stable with a very short period (such as 3 to 5 years), it is reasonable to conclude that the block maxima of the overall level and each sub-dimension of digital finance have upper bounds.

Table 3 displays the GEV fitting results for household economic variables. According to these results, the shape parameters for all variables are positive, meaning that the maximum and minimum values of household economic variables follow type II GEV (Fréchet) distribution, and there are no upper bounds for these values. Intuitively, there are different interpretations for the maxima and minima results. First, for the maxima, the fact that there are no upper bounds indicates that the household financial variables have not yet shown an upper bound limit by certain factors during the sample period due to the rapid economic growth. Second, for the minima, the "unbounded" results do not necessarily mean that the values of these minimum economic variables are "not small" but highlight that there are pretty wide gaps between the minima and maxima values of these economic variables. Therefore, their domain of attractions is Fréchet distribution, which implies that they may have "nearly unlimited" upside potential. Additional evidence for the above explanation comes from the GEV estimation results for location parameters, which are highly associated with the other two GEV parameters. As can be seen from Table 3, the location parameters for block minima are much smaller than that of the corresponding block maxima, especially for the provincial level. For example, the location parameters of income, consumption, and financial asset holding at the provincial level are $0.0458,0.9184$, and 0.0089 for block minima, and 3.0422, 4.6220, and 10.8559 for block maxima. To some extent, the result of GEV fitting for household economic variables reveals the existing gaps in these economic 
Table 3 The GEV estimations for household economic variables

\begin{tabular}{|c|c|c|c|c|c|}
\hline & Variables & Scope & $\xi$ & $\sigma$ & $\mu$ \\
\hline \multirow[t]{6}{*}{ Block minima } & \multirow[t]{2}{*}{ Income } & City & $\begin{array}{l}0.7149 \\
(0.0720)\end{array}$ & $\begin{array}{l}0.5368 \\
(0.0350)\end{array}$ & $\begin{array}{l}0.4539 \\
(0.0327)\end{array}$ \\
\hline & & Province & $\begin{array}{l}1.88320 \\
(0.4829)\end{array}$ & $\begin{array}{l}0.09155 \\
(0.0149)\end{array}$ & $\begin{array}{l}0.0458 \\
(0.0102)\end{array}$ \\
\hline & \multirow[t]{2}{*}{ Consumption } & City & $\begin{array}{l}0.3326 \\
(0.0463)\end{array}$ & $\begin{array}{l}2.2151 \\
(0.1072)\end{array}$ & $\begin{array}{l}2.8286 \\
(0.1244)\end{array}$ \\
\hline & & Province & $\begin{array}{l}0.5137 \\
(0.1192)\end{array}$ & $\begin{array}{l}0.8733 \\
(0.1121)\end{array}$ & $\begin{array}{l}0.9184 \\
(0.1160)\end{array}$ \\
\hline & \multirow[t]{2}{*}{ Financial asset holding } & City & $\begin{array}{l}1.1465 \\
(0.0851)\end{array}$ & $\begin{array}{l}0.2614 \\
(0.0217)\end{array}$ & $\begin{array}{l}0.1816 \\
(0.0157)\end{array}$ \\
\hline & & Province & $\begin{array}{l}3.4899 \\
(0.0109)\end{array}$ & $\begin{array}{l}0.0277 \\
(0.000002)\end{array}$ & $\begin{array}{l}0.0089 \\
(0.000002)\end{array}$ \\
\hline \multirow[t]{6}{*}{ Block maxima } & \multirow[t]{2}{*}{ Income } & City & $\begin{array}{l}0.6484 \\
(0.0518)\end{array}$ & $\begin{array}{l}0.6733 \\
(0.0397)\end{array}$ & $\begin{array}{l}0.8828 \\
(0.0373)\end{array}$ \\
\hline & & Province & $\begin{array}{l}0.7441 \\
(0.1535)\end{array}$ & $\begin{array}{l}2.8382 \\
(0.4355)\end{array}$ & $\begin{array}{l}3.0422 \\
(0.3920)\end{array}$ \\
\hline & \multirow[t]{2}{*}{ Consumption } & City & $\begin{array}{l}0.2545 \\
(0.0399)\end{array}$ & $\begin{array}{l}1.0909 \\
(0.0492)\end{array}$ & $\begin{array}{l}2.2667 \\
(0.0601)\end{array}$ \\
\hline & & Province & $\begin{array}{l}0.3665 \\
(0.1201)\end{array}$ & $\begin{array}{l}2.1544 \\
(0.2571)\end{array}$ & $\begin{array}{l}4.6220 \\
(0.2921)\end{array}$ \\
\hline & \multirow[t]{2}{*}{ Financial asset holding } & City & $\begin{array}{l}0.5503 \\
(0.0511)\end{array}$ & $\begin{array}{l}3.0420 \\
(0.1690)\end{array}$ & $\begin{array}{l}3.6377 \\
(0.1704)\end{array}$ \\
\hline & & Province & $\begin{array}{l}0.6956 \\
(0.1610)\end{array}$ & $\begin{array}{l}9.0206 \\
(1.3681)\end{array}$ & $\begin{array}{l}10.8559 \\
(1.2772)\end{array}$ \\
\hline
\end{tabular}

dimensions and therefore implies the need for economic fairness.

\subsection{The BET results}

To detect whether or not there exist nonlinear dependence between the block maxima and/or minima within each constructed extreme pair, this paper utilizes binary expansion testing (BET) proposed by Zhang [34] to outline the dependent situation of each variable in dimensions (Min to Min, Max to Max, and Max to Min). The resulting BETstats and corresponding $p$ values at depth $=1$, and up to 2, 3, and 4 are listed in Tables 4, 5, 6, and 7.

According to Tables 4, 5, 6, and 7, the BET results with different depths share a lot in common, demonstrating the robustness of our results. The main findings of BET can be summarized as follows.

First, the digital finance and household economic variables generally show very strong dependences in the Min to Min dimension, especially for contemporaneous effects. In Tables 4, 5, 6, and 7, income and asset holding are contemporaneously (Lag = "No") dependent with index aggregate at 0.01 level in both city-level and provincial level. The contemporaneous dependence between consumption and index aggregate is also strong (at 0.01 or 0.05 level), whereas it varies by scope and depth. Meanwhile, many dependencies on sub-indexes are also detected. For the intertemporal
(Lag = "Yes") dependence, income, consumption, and asset holding all show dependence on index aggregate at different significant levels with different depths at the city-level. Nevertheless, the intertemporal dependence relationships become insignificant at the provincial level; even some of the household economic variables still show a significant dependence on digital financial sub-indexes under this situation. The above BET results preliminarily reveal that the behavior of the "poorest" household in a region is likely to be associated with the "worst" level of digital finance development in the region. This inspires us to further quantify the tail dependences between digital finance and household financial variables to clarify the former's role in welfare and social equity, which will be discussed via the TQCC results in "Section 4.3."

Second, the pattern of the results for the Max to Max pairs is quite similar to that of Min to Min pairs. Two main findings can be summarized from related results: (1) given the same scope, the contemporaneous effects are generally larger than the intertemporal effects and (2) given contemporaneous effect or intertemporal effect, the dependences at the city-level are generally larger than that at the provincial level.

Third, except for a few sub-digital finance indexes, the independent null hypothesis cannot be rejected in the Max to Min dimension. Tables 4, 5, 6, and 7 shows that the dependence between all household economic variables and index 
Table 4 BET results at depth is equal to 1

\begin{tabular}{|c|c|c|c|c|c|c|c|c|c|c|c|}
\hline \multirow[t]{2}{*}{ Pair } & \multirow[t]{2}{*}{ Scope } & \multirow[t]{2}{*}{ Lag } & \multirow[t]{2}{*}{ Variable } & \multicolumn{2}{|c|}{ Index aggregate } & \multicolumn{2}{|c|}{ Coverage breadth } & \multicolumn{2}{|c|}{ Usage depth } & \multicolumn{2}{|c|}{ Digitization level } \\
\hline & & & & $z$-statistic & $p$ value & $z$-statistic & $p$ value & $z$-statistic & $p$ value & $z$-statistic & $p$ value \\
\hline \multirow[t]{12}{*}{ Min to Min } & \multirow[t]{6}{*}{ City } & \multirow[t]{3}{*}{ No } & Income & $7.6913 * * *$ & 0.0000 & $7.2045^{* * *}$ & 0.0000 & $2.0445^{* *}$ & 0.0466 & $2.5313 * *$ & 0.0123 \\
\hline & & & Consumption & $4.8679 * * *$ & 0.0000 & $1.7524^{*}$ & 0.0894 & $2.2392 * *$ & 0.0289 & $3.5049 * * *$ & 0.0005 \\
\hline & & & Asset & $8.3728 * * *$ & 0.0000 & 0.6815 & 0.5284 & $3.4075 * * *$ & 0.0007 & $3.1154 * * *$ & 0.0020 \\
\hline & & \multirow[t]{3}{*}{ Yes } & Income & $2.5189 * *$ & 0.0143 & $2.9988^{* * *}$ & 0.0034 & $3.2387 * * *$ & 0.0015 & 0.7197 & 0.5118 \\
\hline & & & Consumption & $2.2790 * *$ & 0.0271 & $2.7588^{* * *}$ & 0.0071 & $3.4786 * * *$ & 0.0006 & 1.1995 & 0.2570 \\
\hline & & & Asset & $2.7588 * * *$ & 0.0071 & $2.0391 * *$ & 0.0487 & 1.4394 & 0.1699 & 1.1995 & 0.2570 \\
\hline & \multirow[t]{6}{*}{ Provincial } & \multirow[t]{3}{*}{ No } & Income & $3.8105 * * *$ & 0.0001 & $3.3486^{* * *}$ & 0.0008 & 0.1154 & 0.9093 & 0.5773 & 0.5674 \\
\hline & & & Consumption & $2.8867 * * *$ & 0.0041 & 0.1154 & 0.9093 & 0.1154 & 0.9093 & $1.9629 *$ & 0.0510 \\
\hline & & & Asset & $3.3486 * * *$ & 0.0008 & 0.8082 & 0.4249 & 1.5011 & 0.1363 & 1.0392 & 0.3030 \\
\hline & & \multirow[t]{3}{*}{ Yes } & Income & 0.8485 & 0.4936 & 0.8485 & 0.4936 & $1.9798 *$ & 0.0722 & 0.2828 & 0.8930 \\
\hline & & & Consumption & 0.8485 & 0.4936 & 1.4142 & 0.2155 & 1.4142 & 0.2155 & 1.4142 & 0.2155 \\
\hline & & & Asset & 1.4142 & 0.2155 & $1.9798^{*}$ & 0.0722 & 0.8485 & 0.4936 & 0.2828 & 0.8930 \\
\hline \multirow[t]{12}{*}{ Max to Max } & \multirow[t]{6}{*}{ City } & \multirow[t]{3}{*}{ No } & Income & $8.0416^{* * *}$ & 0.0000 & $7.6517 * * *$ & 0.0000 & $4.7274 * * *$ & 0.0000 & $5.4098 * * *$ & 0.0000 \\
\hline & & & Consumption & $5.7022 * * *$ & 0.0000 & $3.9476 * * *$ & 0.0001 & $3.3628 * * *$ & 0.0008 & $4.8249 * * *$ & 0.0000 \\
\hline & & & Asset & $8.4315 * * *$ & 0.0000 & $4.7274 * * *$ & 0.0000 & $5.6047 * * *$ & 0.0000 & $3.6552 * * *$ & 0.0002 \\
\hline & & \multirow[t]{3}{*}{ Yes } & Income & $2.5189 * *$ & 0.0143 & $2.5189 * *$ & 0.0143 & 1.3194 & 0.2102 & 0 & 1.0000 \\
\hline & & & Consumption & $2.5189 * *$ & 0.0143 & 0.1199 & 0.9526 & 1.0795 & 0.3105 & 0.4798 & 0.6763 \\
\hline & & & Asset & $2.5189 * *$ & 0.0143 & 0.5997 & 0.5915 & 0.2399 & 0.8581 & 1.4394 & 0.1696 \\
\hline & \multirow[t]{6}{*}{ Provincial } & \multirow[t]{3}{*}{ No } & Income & $3.1176^{* * *}$ & 0.0019 & $2.6558 * * *$ & 0.0083 & 1.2701 & 0.2097 & $2.4248 * *$ & 0.0161 \\
\hline & & & Consumption & $3.5795 * * *$ & 0.0003 & 1.2701 & 0.2097 & 1.2701 & 0.2097 & $1.9629 *$ & 0.0518 \\
\hline & & & Asset & $2.6558 * * *$ & 0.0083 & 1.2701 & 0.2097 & $2.4248 * *$ & 0.0161 & $2.4248 * *$ & 0.0161 \\
\hline & & \multirow[t]{3}{*}{ Yes } & Income & 0.2828 & 0.8930 & 0.8485 & 0.4936 & 1.4142 & 0.2155 & $1.9798 *$ & 0.0722 \\
\hline & & & Consumption & 1.4142 & 0.2155 & 0.2828 & 0.8930 & 0.8485 & 0.4936 & 0.2828 & 0.8930 \\
\hline & & & Asset & 0.8485 & 0.4936 & 0.8485 & 0.4936 & 0.8485 & 0.4936 & 0.2828 & 0.8930 \\
\hline \multirow[t]{12}{*}{ Max to Min } & \multirow[t]{6}{*}{ City } & No & Income & 0.9801 & 0.3356 & 0.4200 & 0.6803 & 1.5403 & 0.1300 & 0.7001 & 0.4925 \\
\hline & & & Consumption & 0.9801 & 0.3356 & 0.4200 & 0.6806 & 1.5403 & 0.1300 & 0.1400 & 0.8909 \\
\hline & & & Asset & 1.2602 & 0.2153 & 0.9801 & 0.3363 & 0.1400 & 0.8909 & 1.2602 & 0.2159 \\
\hline & & Yes & Income & 0.1400 & 0.8909 & 1.2602 & 0.2159 & 0.1400 & 0.8909 & $1.5403^{*}$ & 0.0981 \\
\hline & & & Consumption & 0.1400 & 0.8909 & $2.3804 * *$ & 0.0186 & 0.1400 & 0.8909 & 0.4200 & 0.6529 \\
\hline & & & Asset & 0.9801 & 0.3363 & $2.3804 * *$ & 0.0186 & $1.5403 *$ & 0.0981 & 0.9801 & 0.2941 \\
\hline & Provincial & No & Income & 1.4142 & 0.2155 & 0.2828 & 0.8930 & $1.9798 *$ & 0.0722 & 0.8485 & 0.4936 \\
\hline & & & Consumption & 0.2828 & 0.8930 & $1.9798^{*}$ & 0.0722 & $1.9798 *$ & 0.0722 & 0.8485 & 0.4936 \\
\hline & & & Asset & 1.4142 & 0.2155 & 1.4142 & 0.2155 & 0.8485 & 0.4936 & 0.2828 & 0.8930 \\
\hline & & Yes & Income & 0.8485 & 0.4936 & 0.2828 & 0.8930 & $1.9798 *$ & 0.0722 & 0.8485 & 0.4936 \\
\hline & & & Consumption & 1.4142 & 0.2155 & $1.9798^{*}$ & 0.0722 & $1.9798 *$ & 0.0722 & 0.2828 & 0.8930 \\
\hline & & & Asset & 0.8485 & 0.4936 & 0.8485 & 0.4936 & 1.4142 & 0.2155 & 0.2828 & 0.8930 \\
\hline
\end{tabular}

*Statistical significance at $10 \%$ level; **Statistical significance at $5 \%$ level; ***Statistical significance at $1 \%$ level

aggregate is insignificant for Max to Min pairs. In Tables 5, 6 , and 7, none of the variables has shown to be dependent on digitization level in the Max to Min dimension. The results regarding Max to Min pairs initially provide us with "good news," that is, no sufficient evidence of the negative effects of the development of digital finance on household finance is found in the BET results.

The above evidence provides us with a valuable basis for the overall dependent situations among digital finance and household economic variables and emphasizes the need for further research to quantify the tail dependence in different extreme pairs and scopes, which will be done in "Section 4.3" using TQCC.

\subsection{The TQCC results}

Based on the GEV estimations and BET results, the TQCC for each pair is computed using Eq. (5) for further investigating tail dependence relationships among variables. Tables 8 and 10 report the full sample TQCC estimations when $u q$ 
Table 5 BET results at depth up to 2

\begin{tabular}{|c|c|c|c|c|c|c|c|c|c|c|c|}
\hline \multirow[t]{2}{*}{ Pair } & \multirow[t]{2}{*}{ Scope } & \multirow[t]{2}{*}{ Lag } & \multirow[t]{2}{*}{ Variable } & \multicolumn{2}{|c|}{ Index aggregate } & \multicolumn{2}{|c|}{ Coverage breadth } & \multicolumn{2}{|c|}{ Usage depth } & \multicolumn{2}{|c|}{ Digitization level } \\
\hline & & & & $z$-statistic & $p$ value & $z$-statistic & $p$ value & $z$-statistic & $p$ value & $z$-statistic & $p$ value \\
\hline \multirow[t]{12}{*}{ Min to Min } & \multirow[t]{6}{*}{ City } & \multirow[t]{3}{*}{ No } & Income & $7.6913 * * *$ & 0.0000 & $7.2045^{* * *}$ & 0.0000 & $2.0445^{*}$ & 0.0931 & $2.5313 * *$ & 0.0246 \\
\hline & & & Consumption & $4.8679 * * *$ & 0.0000 & $2.9207 * *$ & 0.0488 & $2.2392 *$ & 0.0578 & $3.5049 * * *$ & 0.0010 \\
\hline & & & Asset & $8.3728 * * *$ & 0.0000 & 1.9471 & 0.7458 & $3.4075 * * *$ & 0.0014 & $3.1154 * * *$ & 0.0039 \\
\hline & & \multirow[t]{3}{*}{ Yes } & Income & $2.5189 * *$ & 0.0285 & $2.9988 * * *$ & 0.0068 & $3.2387 * * *$ & 0.0030 & 0.7197 & 1.0000 \\
\hline & & & Consumption & $2.2790^{*}$ & 0.0541 & $2.7588^{* *}$ & 0.0143 & $3.4786 * * *$ & 0.0013 & 1.1995 & 0.5139 \\
\hline & & & Asset & $2.7588 * *$ & 0.0143 & $2.0391 *$ & 0.0975 & 1.4394 & 0.3397 & 1.1995 & 0.5139 \\
\hline & \multirow[t]{6}{*}{ Provincial } & \multirow[t]{3}{*}{ No } & Income & $3.8105 * * *$ & 0.0003 & $3.3486 * * *$ & 0.0016 & 1.9629 & 0.8315 & 2.1939 & 0.4698 \\
\hline & & & Consumption & $2.8867 * * *$ & 0.0081 & 1.9629 & 0.8315 & 1.2701 & 1.0000 & 1.9629 & 0.1021 \\
\hline & & & Asset & $3.3486^{* * *}$ & 0.0016 & 1.9629 & 0.8315 & 1.5011 & 0.2727 & 1.0392 & 0.6060 \\
\hline & & \multirow[t]{3}{*}{ Yes } & Income & 2.2627 & 0.5982 & 0.8485 & 0.9871 & 1.9798 & 0.1445 & $3.3941 * *$ & 0.0195 \\
\hline & & & Consumption & 0.8485 & 0.9871 & 2.8284 & 0.1277 & $3.3941 * *$ & 0.0195 & 2.2627 & 0.2942 \\
\hline & & & Asset & 1.4142 & 0.4311 & $3.1112 *$ & 0.0512 & 0.8485 & 0.9871 & 1.6970 & 1.0000 \\
\hline \multirow[t]{12}{*}{ Max to Max } & \multirow[t]{6}{*}{ City } & \multirow[t]{3}{*}{ No } & Income & $8.0416^{* * *}$ & 0.0000 & $7.6517 * * *$ & 0.0000 & $4.7274 * * *$ & 0.0000 & $5.4098 * * *$ & 0.0000 \\
\hline & & & Consumption & $5.7022 * * *$ & 0.0000 & $3.9476 * * *$ & 0.0002 & $3.3628 * * *$ & 0.0015 & $4.8249 * * *$ & 0.0000 \\
\hline & & & Asset & $8.4315 * * *$ & 0.0000 & $4.7274 * * *$ & 0.0000 & $5.6047 * * *$ & 0.0000 & $3.6552 * * *$ & 0.0005 \\
\hline & & \multirow[t]{3}{*}{ Yes } & Income & $3.3586^{* *}$ & 0.0159 & $2.5189 * *$ & 0.0285 & $2.8788^{*}$ & 0.0790 & 0 & 1.0000 \\
\hline & & & Consumption & $2.5189 * *$ & 0.0285 & 1.9192 & 1.0000 & 2.7588 & 0.1141 & 0.4798 & 1.0000 \\
\hline & & & Asset & $3.3586^{* *}$ & 0.0159 & 0.5997 & 1.0000 & 2.2790 & 0.3172 & 1.4394 & 0.3392 \\
\hline & \multirow[t]{6}{*}{ Provincial } & \multirow[t]{3}{*}{ No } & Income & $3.1176^{* * *}$ & 0.0038 & $2.6558 * *$ & 0.0167 & 1.2701 & 0.4194 & $2.4248 * *$ & 0.0321 \\
\hline & & & Consumption & $3.5795 * * *$ & 0.0007 & $3.1176^{* *}$ & 0.0303 & 1.2701 & 0.4194 & 1.9629 & 0.1037 \\
\hline & & & Asset & $2.6558 * *$ & 0.0167 & 1.2701 & 0.4194 & $2.4248 * *$ & 0.0321 & $2.4248 * *$ & 0.0321 \\
\hline & & \multirow[t]{3}{*}{ Yes } & Income & 2.5455 & 0.2893 & 0.8485 & 0.9871 & 1.4142 & 0.4311 & 1.9798 & 0.1445 \\
\hline & & & Consumption & 1.4142 & 0.4311 & 1.9798 & 1.0000 & 0.8485 & 0.9871 & 1.4142 & 1.0000 \\
\hline & & & Asset & 2.8284 & 0.1277 & 0.8485 & 0.9871 & 0.8485 & 0.9871 & 1.1313 & 1.0000 \\
\hline \multirow[t]{12}{*}{ Max to Min } & \multirow[t]{6}{*}{ City } & No & Income & 0.9801 & 0.6712 & 2.6605 & 0.1346 & 1.5403 & 0.2599 & 0.7001 & 0.9850 \\
\hline & & & Consumption & 2.1004 & 0.6131 & 2.3804 & 0.2982 & 1.5403 & 0.2599 & 1.5403 & 1.0000 \\
\hline & & & Asset & 1.2602 & 0.4305 & 0.9801 & 0.6726 & 1.8203 & 1.0000 & 1.2602 & 0.4318 \\
\hline & & Yes & Income & 1.8203 & 1.0000 & 2.3804 & 0.2982 & 2.1004 & 0.6131 & 1.5403 & 0.1962 \\
\hline & & & Consumption & 1.8203 & 1.0000 & $2.3804 * *$ & 0.0373 & 2.3804 & 0.2982 & 1.8203 & 1.0000 \\
\hline & & & Asset & 2.1004 & 0.6131 & $2.3804 * *$ & 0.0373 & 1.5403 & 0.1962 & 0.9801 & 0.5881 \\
\hline & Provincial & No & Income & 1.4142 & 0.4311 & 1.4142 & 1.0000 & 1.9798 & 0.1445 & 0.8485 & 0.9871 \\
\hline & & & Consumption & 1.4142 & 1.0000 & 1.9798 & 0.1445 & $2.8284 *$ & 0.0593 & 2.2627 & 0.2713 \\
\hline & & & Asset & 2.5455 & 0.1412 & 1.4142 & 0.4311 & 2.2627 & 0.2713 & 1.6970 & 1.0000 \\
\hline & & Yes & Income & 0.8485 & 0.9871 & 1.4142 & 1.0000 & 1.9798 & 0.1445 & 0.8485 & 0.9871 \\
\hline & & & Consumption & 1.4142 & 0.4311 & $3.3941 * *$ & 0.0195 & 1.9798 & 0.1445 & 2.2627 & 0.2713 \\
\hline & & & Asset & 0.8485 & 0.9871 & 0.8485 & 0.9871 & 2.2627 & 0.2942 & 1.6970 & 1.0000 \\
\hline
\end{tabular}

*Statistical significance at $10 \%$ level; **Statistical significance at $5 \%$ level; ***Statistical significance at $1 \%$ level

is equal to 0.90 and 0.95 , respectively. The corresponding $p$ values are displayed in Tables 9 and 11 .

According to the tables above, it is shown that the major findings are pretty similar for TQCCs under $u q=0.90$ and 0.95 . Much meaningful information can be obtained from the TQCC results. The main findings are summarized as follows.

First, household income shows significant tail dependence with the aggregate and sub-indexes of digital finance in most of the cases of Min to Min pairs, which strongly highlights the poverty reduction effect of digital finance development. As shown in Tables 9 and 11, except for the contemporaneous effect of digitization level, all TQCCs (for aggregate index and other sub-indexes) are significant at 0.01 level. According to Tables 8 and 10, numerically, the provincial TQCCs for income and aggregate index with $u q$ equal 0.90 and 0.95 are greater than 0.7 and 0.9 , respectively; and the city-level contemporaneous TQCCs with $u q$ equal 0.90 and 0.95 are larger than 0.3 and 0.6 , respectively. Compared with existing empirical examples using TQCC 
Table 6 BET results at depth up to 3

\begin{tabular}{|c|c|c|c|c|c|c|c|c|c|c|c|}
\hline \multirow[t]{2}{*}{ Pair } & \multirow[t]{2}{*}{ Scope } & \multirow[t]{2}{*}{ Lag } & \multirow[t]{2}{*}{ Variable } & \multicolumn{2}{|c|}{ Index aggregate } & \multicolumn{2}{|c|}{ Coverage breadth } & \multicolumn{2}{|c|}{ Usage depth } & \multicolumn{2}{|c|}{ Digitization level } \\
\hline & & & & $z$-statistic & $p$ value & $z$-statistic & $p$ value & $z$-statistic & $p$ value & $z$-statistic & $p$ value \\
\hline \multirow[t]{12}{*}{ Min to Min } & \multirow[t]{6}{*}{ City } & \multirow[t]{3}{*}{ No } & Income & $7.6913 * * *$ & 0.0000 & $7.2045^{* * *}$ & 0.0000 & 2.0445 & 0.1397 & $2.5313 * *$ & 0.0369 \\
\hline & & & Consumption & $4.8679 * * *$ & 0.0000 & $2.9207^{*}$ & 0.0732 & $2.2392 *$ & 0.0867 & $3.5049 * * *$ & 0.0014 \\
\hline & & & Asset & $8.3728 * * *$ & 0.0000 & 2.7260 & 0.9046 & $3.4075 * * *$ & 0.0021 & $3.1154 * * *$ & 0.0059 \\
\hline & & \multirow[t]{3}{*}{ Yes } & Income & $2.5189 * *$ & 0.0428 & $2.9988 * *$ & 0.0101 & $3.2387 * * *$ & 0.0045 & $3.4786^{* *}$ & 0.0489 \\
\hline & & & Consumption & $2.2790 *$ & 0.0812 & $2.7588^{* *}$ & 0.0214 & $3.4786 * * *$ & 0.0019 & 1.1995 & 0.7709 \\
\hline & & & Asset & $2.7588 * *$ & 0.0214 & 2.0391 & 0.1462 & 3.2387 & 0.1207 & $3.5985^{* *}$ & 0.0463 \\
\hline & \multirow[t]{6}{*}{ Provincial } & \multirow[t]{3}{*}{ No } & Income & $3.8105 * * *$ & 0.0004 & $3.3486^{* * *}$ & 0.0025 & 3.1176 & 0.2271 & 2.1939 & 0.7048 \\
\hline & & & Consumption & $2.8867 * *$ & 0.0122 & 1.9629 & 1.0000 & 2.6558 & 0.9918 & 1.9629 & 0.1531 \\
\hline & & & Asset & $3.3486 * * *$ & 0.0025 & 1.9629 & 1.0000 & 1.5011 & 0.4090 & 1.0392 & 0.9090 \\
\hline & & \multirow[t]{3}{*}{ Yes } & Income & 2.2627 & 0.8974 & 0.8485 & 1.0000 & 1.9798 & 0.2167 & $3.3941 * *$ & 0.0292 \\
\hline & & & Consumption & 3.1112 & 0.3836 & 2.8284 & 0.1916 & $3.3941 * *$ & 0.0292 & 2.2627 & 0.4413 \\
\hline & & & Asset & 1.4142 & 0.6466 & $3.1112 *$ & 0.0767 & 0.8485 & 1.0000 & 2.5455 & 1.0000 \\
\hline \multirow[t]{12}{*}{ Max to Max } & \multirow[t]{6}{*}{ City } & \multirow[t]{3}{*}{ No } & Income & $8.0416^{* * *}$ & 0.0000 & $7.6517 * * *$ & 0.0000 & $4.7274 * * *$ & 0.0000 & $5.4098 * * *$ & 0.0000 \\
\hline & & & Consumption & $5.7022 * * *$ & 0.0000 & $3.9476 * * *$ & 0.0002 & $3.3628 * * *$ & 0.0023 & $4.8249 * * *$ & 0.0000 \\
\hline & & & Asset & $8.4315 * * *$ & 0.0000 & $4.7274 * * *$ & 0.0000 & $5.6047 * * *$ & 0.0000 & $3.6552 * * *$ & 0.0007 \\
\hline & & \multirow[t]{3}{*}{ Yes } & Income & $3.3586^{* *}$ & 0.0238 & $2.5189 * *$ & 0.0428 & 2.8788 & 0.1185 & 0 & 1.0000 \\
\hline & & & Consumption & $2.5189 * *$ & 0.0428 & 2.7588 & 0.8548 & 2.7588 & 0.1711 & 0.4798 & 1.0000 \\
\hline & & & Asset & $3.3586^{* *}$ & 0.0238 & 0.5997 & 1.0000 & 2.2790 & 0.4758 & 1.4394 & 0.5088 \\
\hline & \multirow[t]{6}{*}{ Provincial } & \multirow[t]{3}{*}{ No } & Income & $3.1176^{* * *}$ & 0.0057 & $2.6558 * *$ & 0.0250 & 1.2701 & 0.6291 & $2.4248 * *$ & 0.0482 \\
\hline & & & Consumption & $3.5795 * * *$ & 0.0010 & $3.1176^{* *}$ & 0.0454 & 1.2701 & 0.6291 & 1.9629 & 0.1555 \\
\hline & & & Asset & $2.6558 * *$ & 0.0250 & 1.2701 & 0.6291 & $2.4248 * *$ & 0.0482 & $2.4248^{* *}$ & 0.0482 \\
\hline & & \multirow[t]{3}{*}{ Yes } & Income & 2.5455 & 0.4339 & 0.8485 & 1.0000 & 2.8284 & 0.4447 & 3.1112 & 0.1675 \\
\hline & & & Consumption & 1.4142 & 0.6466 & 1.9798 & 1.0000 & 0.8485 & 1.0000 & 2.2627 & 1.0000 \\
\hline & & & Asset & 2.8284 & 0.1916 & 2.8284 & 0.4447 & $3.6769 * *$ & 0.0478 & 1.9798 & 1.0000 \\
\hline \multirow[t]{12}{*}{ Max to Min } & \multirow[t]{6}{*}{ City } & No & Income & 0.9801 & 1.0000 & 2.6605 & 0.2019 & 1.5403 & 0.3899 & 0.7001 & 1.0000 \\
\hline & & & Consumption & 2.1004 & 0.9197 & 2.3804 & 0.4472 & 1.5403 & 0.3899 & 2.1004 & 1.0000 \\
\hline & & & Asset & 1.2602 & 0.6458 & 2.6605 & 0.9932 & 1.8203 & 1.0000 & 1.2602 & 0.6477 \\
\hline & & Yes & Income & 2.6605 & 1.0000 & 2.3804 & 0.4472 & 2.1004 & 0.9197 & 1.5403 & 0.2943 \\
\hline & & & Consumption & 1.8203 & 1.0000 & $2.3804^{*}$ & 0.0559 & 2.3804 & 0.4472 & 1.8203 & 1.0000 \\
\hline & & & Asset & 2.1004 & 0.9197 & $2.3804^{*}$ & 0.0559 & 1.5403 & 0.2943 & 0.9801 & 0.8822 \\
\hline & Provincial & No & Income & 3.1112 & 0.3836 & 2.2627 & 1.0000 & 1.9798 & 0.2167 & 0.8485 & 1.0000 \\
\hline & & & Consumption & 2.5455 & 1.0000 & 1.9798 & 0.2167 & $2.8284 *$ & 0.0889 & 2.2627 & 0.4069 \\
\hline & & & Asset & 2.5455 & 0.2118 & 1.4142 & 0.6466 & 2.2627 & 0.4069 & 2.8284 & 0.9169 \\
\hline & & Yes & Income & 0.8485 & 1.0000 & 2.5455 & 1.0000 & 1.9798 & 0.2167 & 0.8485 & 1.0000 \\
\hline & & & Consumption & 3.1112 & 0.3943 & $3.3941 * *$ & 0.0292 & 1.9798 & 0.2167 & 2.2627 & 0.4069 \\
\hline & & & Asset & 0.8485 & 1.0000 & 0.8485 & 1.0000 & 2.2627 & 0.4413 & 2.5455 & 1.0000 \\
\hline
\end{tabular}

*Statistical significance at $10 \%$ level; **Statistical significance at $5 \%$ level; ***Statistical significance at $1 \%$ level

$[33,35]$, these values are very high. This reveals that the tail dependences of these pairs are extremely strong. Using 0.6081 (the city-level contemporaneous TQCC value for household income and the aggregate index when $u q=0.95$ ) as an example, 0.6081 means there is a $60.81 \%$ of chance that given the "worst" digital financial level is improved, the "poorest" situation of household will be improved at the same time. Other TQCC values are interpreted similarly.

The above findings regarding tail dependence in the Min to Min dimension are of great and important economic interpretation. A significantly strong tail dependence between digital finance and household income intuitively means that improving the "worst" digital finance in a region increases the income of the "poorest" households. This can be seen as the poverty reduction effect from the extreme perspective. In addition, since most of the TQCCs are significant in both cases that with and without taking lag for the digital finance variables, we can further conclude that the marginal benefits of the "worst" digital financial 
Table 7 BET results at depth up to 4

\begin{tabular}{|c|c|c|c|c|c|c|c|c|c|c|c|}
\hline \multirow[t]{2}{*}{ Pair } & \multirow[t]{2}{*}{ Scope } & \multirow[t]{2}{*}{ Lag } & \multirow[t]{2}{*}{ Variable } & \multicolumn{2}{|c|}{ Index aggregate } & \multicolumn{2}{|c|}{ Coverage breadth } & \multicolumn{2}{|l|}{ Usage depth } & \multicolumn{2}{|c|}{ Digitization level } \\
\hline & & & & $z$-statistic & $p$ value & $z$-statistic & $p$ value & $z$-statistic & $p$ value & $z$-statistic & $p$ value \\
\hline \multirow[t]{12}{*}{ Min to Min } & \multirow[t]{6}{*}{ City } & \multirow[t]{3}{*}{ No } & income & $7.6913 * * *$ & 0.0000 & $7.2045 * * *$ & 0.0000 & 2.0445 & 0.1862 & $2.5313 * *$ & 0.0491 \\
\hline & & & consumption & $4.8679 * * *$ & 0.0000 & $2.9207^{*}$ & 0.0976 & 2.2392 & 0.1156 & $3.5049 * * *$ & 0.0019 \\
\hline & & & asset & $8.3728 * * *$ & 0.0000 & 2.7260 & 1.0000 & $3.4075 * * *$ & 0.0028 & $3.1154 * * *$ & 0.0079 \\
\hline & & \multirow[t]{3}{*}{ Yes } & income & $2.5189 *$ & 0.0571 & $2.9988 * *$ & 0.0135 & $3.2387 * * *$ & 0.0061 & $3.4786^{*}$ & 0.0651 \\
\hline & & & consumption & 2.2790 & 0.1083 & $2.7588 * *$ & 0.0285 & $3.4786 * * *$ & 0.0026 & 1.1995 & 1.0000 \\
\hline & & & asset & $2.7588 * *$ & 0.0285 & 2.0391 & 0.1949 & 3.2387 & 0.1609 & $3.5985^{*}$ & 0.0618 \\
\hline & \multirow[t]{6}{*}{ Provincial } & \multirow[t]{3}{*}{ No } & income & $3.8105 * * *$ & 0.0005 & $3.3486 * * *$ & 0.0033 & 3.1176 & 0.3029 & $3.8105^{*}$ & 0.0792 \\
\hline & & & consumption & $2.8867 * *$ & 0.0162 & 1.9629 & 1.0000 & 3.1176 & 1.0000 & 1.9629 & 0.2041 \\
\hline & & & asset & $3.3486 * * *$ & 0.0033 & 1.9629 & 1.0000 & 1.5011 & 0.5453 & 1.0392 & 1.0000 \\
\hline & & \multirow[t]{3}{*}{ Yes } & income & 2.2627 & 1.0000 & 0.8485 & 1.0000 & 1.9798 & 0.2889 & $3.3941 * *$ & 0.0389 \\
\hline & & & consumption & 3.1112 & 0.5115 & 2.8284 & 0.2555 & $3.3941 * *$ & 0.0389 & 2.2627 & 0.5884 \\
\hline & & & asset & 1.4142 & 0.8621 & 3.1112 & 0.1023 & 0.8485 & 1.0000 & 2.5455 & 1.0000 \\
\hline \multirow[t]{12}{*}{ Max to Max } & \multirow[t]{6}{*}{ City } & \multirow[t]{3}{*}{ No } & income & $8.0416 * * *$ & 0.0000 & $7.6517 * * *$ & 0.0000 & $4.7274 * * *$ & 0.0000 & $5.4098 * * *$ & 0.0000 \\
\hline & & & consumption & $5.7022 * * *$ & 0.0000 & $3.9476^{* * *}$ & 0.0003 & $3.3628 * * *$ & 0.0031 & $4.8249 * * *$ & 0.0000 \\
\hline & & & asset & $8.4315 * * *$ & 0.0000 & $4.7274 * * *$ & 0.0000 & $5.6047 * * *$ & 0.0000 & $3.6552 * * *$ & 0.0009 \\
\hline & & \multirow[t]{3}{*}{ Yes } & income & $3.3586^{* *}$ & 0.0317 & $2.5189 *$ & 0.0571 & 2.8788 & 0.1580 & 0 & 1.0000 \\
\hline & & & consumption & $2.5189^{*}$ & 0.0571 & 3.8384 & 0.1122 & 2.7588 & 0.2281 & 2.8788 & 1.0000 \\
\hline & & & asset & $3.3586^{* *}$ & 0.0317 & 0.5997 & 1.0000 & 2.2790 & 0.6344 & 1.4394 & 0.6784 \\
\hline & \multirow[t]{6}{*}{ Provincial } & \multirow[t]{3}{*}{ No } & income & $3.1176^{* * *}$ & 0.0076 & $2.6558^{* *}$ & 0.0333 & 1.2701 & 0.8388 & $2.4248 *$ & 0.0643 \\
\hline & & & consumption & $3.5795 * * *$ & 0.0014 & $3.1176^{*}$ & 0.0606 & 1.2701 & 0.8388 & 1.9629 & 0.2073 \\
\hline & & & asset & $2.6558 * *$ & 0.0333 & 1.2701 & 0.8388 & $2.4248 *$ & 0.0643 & $2.4248 *$ & 0.0643 \\
\hline & & \multirow[t]{3}{*}{ Yes } & income & 2.5455 & 0.5786 & 0.8485 & 1.0000 & 2.8284 & 0.5929 & 3.1112 & 0.2233 \\
\hline & & & consumption & 3.6769 & 0.1131 & 1.9798 & 1.0000 & 0.8485 & 1.0000 & 2.8284 & 1.0000 \\
\hline & & & asset & 2.8284 & 0.2555 & 2.8284 & 0.5929 & $3.6769 *$ & 0.0637 & 2.8284 & 1.0000 \\
\hline \multirow[t]{12}{*}{ Max to Min } & \multirow[t]{6}{*}{ City } & No & income & 0.9801 & 1.0000 & 2.6605 & 0.2692 & 1.5403 & 0.5199 & 0.7001 & 1.0000 \\
\hline & & & consumption & 2.1004 & 1.0000 & 3.5007 & 0.3245 & 1.5403 & 0.5199 & 2.6605 & 1.0000 \\
\hline & & & asset & 1.2602 & 0.8611 & 2.6605 & 1.0000 & 2.9405 & 1.0000 & 1.2602 & 0.8636 \\
\hline & & Yes & income & 2.6605 & 1.0000 & 2.3804 & 0.5963 & 2.1004 & 1.0000 & 1.5403 & 0.3924 \\
\hline & & & consumption & 1.8203 & 1.0000 & $2.3804 *$ & 0.0745 & 2.3804 & 0.5963 & 2.9405 & 1.0000 \\
\hline & & & asset & 3.2206 & 0.8556 & $2.3804^{*}$ & 0.0745 & 3.7807 & 0.1013 & 0.9801 & 1.0000 \\
\hline & Provincial & No & income & 3.1112 & 0.5115 & 3.1112 & 1.0000 & 1.9798 & 0.2889 & 0.8485 & 1.0000 \\
\hline & & & consumption & 2.5455 & 1.0000 & 1.9798 & 0.2889 & 2.8284 & 0.1186 & 2.2627 & 0.5425 \\
\hline & & & asset & 2.5455 & 0.2824 & 1.4142 & 0.8621 & 2.2627 & 0.5425 & 2.8284 & 1.0000 \\
\hline & & Yes & income & 0.8485 & 1.0000 & 2.8284 & 1.0000 & 3.6769 & 0.2838 & 0.8485 & 1.0000 \\
\hline & & & consumption & 3.1112 & 0.5257 & $3.3941 * *$ & 0.0389 & 1.9798 & 0.2889 & 2.2627 & 0.5425 \\
\hline & & & asset & 3.6769 & 0.1131 & 0.8485 & 1.0000 & 2.2627 & 0.5884 & 2.5455 & 1.0000 \\
\hline
\end{tabular}

*Statistical significance at $10 \%$ level; **Statistical significance at $5 \%$ level; ***Statistical significance at $1 \%$ level

improvement to the "poorest" will be reflected in both the same period and the next period.

Besides, since we are modeling block maxima and/ or block minima in a wider region (city or province) containing several sub-regions in this research, the "poorest" households and the "worst" digital financial construction may belong to different sub-regions within the same wider region. In other words, the tail dependence studied in this paper can also be regarded as the spatial correlation between the development of digital finance in a sub-region and household finance in adjunct areas. Thus, the fact that the TQCCs for the Min to Min pairs show significantly strong dependences at both city-level and provincial levels can be seen as evidence for the spatial spillover effect of digital finance in poverty reduction. Moreover, according to Tables 8 and 10, the TQCC values at the provincial levels are generally greater than that at the corresponding citylevel, which indicates that the wider the scope, the greater the spillover effect. The result regarding positive spatial 
Table 8 The TQCC estimation between digital finance indexes and household finance variables with $u q=0.90$

\begin{tabular}{|c|c|c|c|c|c|c|c|}
\hline & Pair & Scope & Lag & Index aggregate & Coverage breadth & Usage depth & Digitization level \\
\hline \multirow[t]{12}{*}{ Income } & Min to Min & City & No & 0.3492 & 0.3766 & 0.0906 & 0.1309 \\
\hline & Min to Min & City & Yes & 0.1179 & 0.0322 & 0.0223 & 0.0503 \\
\hline & Min to Min & Province & No & 0.8842 & 0.9510 & 0.5532 & 0.0248 \\
\hline & Min to Min & Province & Yes & 0.7021 & 0.7543 & 0.2919 & 0.3387 \\
\hline & Max to Max & City & No & 0.0152 & 0.0125 & 0.0285 & 0.0179 \\
\hline & Max to Max & City & Yes & 0.0116 & 0.0062 & 0.0168 & 0.0183 \\
\hline & Max to Max & Province & No & 0.2397 & 0.1379 & 0.3231 & 0.3837 \\
\hline & Max to Max & Province & Yes & 0.1504 & 0.2232 & 0.2700 & 0.7032 \\
\hline & Max to Min & City & No & 0.0005 & 0.0008 & 0.0098 & 0.0010 \\
\hline & Max to Min & City & Yes & 0.0013 & 0.0002 & 0.0049 & 0.0088 \\
\hline & Max to Min & Province & No & 0.0268 & 0.0086 & 0.2190 & 0.0610 \\
\hline & Max to Min & Province & Yes & 0.0164 & 0.0739 & 0.1428 & 0.6238 \\
\hline \multirow[t]{12}{*}{ Consumption } & Min to Min & City & No & 0.2493 & 0.2688 & 0.0657 & 0.0943 \\
\hline & Min to Min & City & Yes & 0.1342 & 0.0390 & 0.0279 & 0.0581 \\
\hline & Min to Min & Province & No & 0.3681 & 0.4329 & 0.1875 & 0.0000 \\
\hline & Min to Min & Province & Yes & 0.4926 & 0.5292 & 0.2047 & 0.2376 \\
\hline & Max to Max & City & No & 0.0018 & 0.0030 & 0.0189 & 0.0015 \\
\hline & Max to Max & City & Yes & 0.0031 & 0.0004 & 0.0112 & 0.0098 \\
\hline & Max to Max & Province & No & 0.0532 & 0.0245 & 0.1778 & 0.0771 \\
\hline & Max to Max & Province & Yes & 0.0489 & 0.1104 & 0.1731 & 0.4948 \\
\hline & Max to Min & City & No & 0.0019 & 0.0020 & 0.0084 & 0.0040 \\
\hline & Max to Min & City & Yes & 0.0036 & 0.0016 & 0.0076 & 0.0116 \\
\hline & Max to Min & Province & No & 0.0177 & 0.0083 & 0.1071 & 0.0349 \\
\hline & Max to Min & Province & Yes & 0.0151 & 0.0518 & 0.1002 & 0.4344 \\
\hline \multirow[t]{12}{*}{ Financial asset holding } & Min to Min & City & No & 0.5149 & 0.5952 & 0.1855 & 0.3050 \\
\hline & Min to Min & City & Yes & 0.1933 & 0.0721 & 0.0481 & 0.0677 \\
\hline & Min to Min & Province & No & 0.2660 & 0.3049 & 0.1355 & 0.0000 \\
\hline & Min to Min & Province & Yes & 0.1901 & 0.2398 & 0.1443 & 0.1074 \\
\hline & Max to Max & City & No & 0.0358 & 0.0285 & 0.0578 & 0.0339 \\
\hline & Max to Max & City & Yes & 0.0344 & 0.0197 & 0.0411 & 0.0439 \\
\hline & Max to Max & Province & No & 0.4494 & 0.2866 & 0.5398 & 0.4743 \\
\hline & Max to Max & Province & Yes & 0.3697 & 0.4694 & 0.5245 & 0.5428 \\
\hline & Max to Min & City & No & 0.0392 & 0.0305 & 0.0647 & 0.0379 \\
\hline & Max to Min & City & Yes & 0.0073 & 0.0039 & 0.0123 & 0.0145 \\
\hline & Max to Min & Province & No & 0.0128 & 0.0071 & 0.0774 & 0.0253 \\
\hline & Max to Min & Province & Yes & 0.0068 & 0.0234 & 0.0453 & 0.3276 \\
\hline
\end{tabular}

externality serves as a byproduct and one of the novelties of this paper.

Second, digital finance has an incentive effect on household income growth and thus improves economic efficiency. For the Max to Max pairs, the contemporaneous tail dependence of income and each digital finance variable is significant at both city and provincial levels, while the intertemporal effect is only significant at the provincial level. According to Tables 9 and 11, except for the intertemporal effect at the city-level, all TQCCs are significant at 0.01 level. For the intertemporal effect at the city-level, the TQCC is 0.0210 (significant at 0.05 level) when the threshold is 0.95 , and is not significant when the threshold is 0.90 . We can infer from these results that the development of the "best" digital finance will indeed bring further wealth effects to the rich, which can be understood as the positive externality of digital finance from an economic perspective. Nevertheless, this positive externality is very limited at the city-level (for example, the TQCC value at the city-level is relatively small, and the intertemporal TQCC is not significant at the 0.90 threshold level) and is relatively stronger at the provincial level (larger than 0.15 in TQCC values for all provincial pairs). These results are consistent with the BET results regarding Max to Max dimension. 
Table $9 p$ values for TQCC between digital finance indexes and household finance variables with $u q=0.90$

\begin{tabular}{|c|c|c|c|c|c|c|c|}
\hline & Pair & Scope & Lag & Index aggregate & Coverage breadth & Usage depth & Digitization level \\
\hline \multirow[t]{12}{*}{ Income } & Min to Min & City & No & 0.0000 & 0.0000 & 0.0000 & 0.0000 \\
\hline & Min to Min & City & Yes & 0.0000 & 0.0013 & 0.0146 & 0.0000 \\
\hline & Min to Min & Province & No & 0.0000 & 0.0000 & 0.0000 & 0.4450 \\
\hline & Min to Min & Province & Yes & 0.0000 & 0.0000 & 0.0000 & 0.0000 \\
\hline & Max to Max & City & No & 0.0122 & 0.0328 & 0.0001 & 0.0046 \\
\hline & Max to Max & City & Yes & 0.1670 & 0.4854 & 0.0537 & 0.0377 \\
\hline & Max to Max & Province & No & 0.0000 & 0.0004 & 0.0000 & 0.0000 \\
\hline & Max to Max & Province & Yes & 0.0046 & 0.0002 & 0.0000 & 0.0000 \\
\hline & Max to Min & City & No & 0.9780 & 0.9522 & 0.0816 & 0.9325 \\
\hline & Max to Min & City & Yes & 0.9506 & 0.9984 & 0.6040 & 0.2964 \\
\hline & Max to Min & Province & No & 0.4026 & 0.8631 & 0.0000 & 0.0576 \\
\hline & Max to Min & Province & Yes & 0.8020 & 0.1166 & 0.0064 & 0.0000 \\
\hline \multirow[t]{12}{*}{ Consumption } & Min to Min & City & No & 0.0000 & 0.0000 & 0.0000 & 0.0000 \\
\hline & Min to Min & City & Yes & 0.0000 & 0.0002 & 0.0038 & 0.0000 \\
\hline & Min to Min & Province & No & 0.0000 & 0.0000 & 0.0000 & 1.0000 \\
\hline & Min to Min & Province & Yes & 0.0000 & 0.0000 & 0.0004 & 0.0001 \\
\hline & Max to Max & City & No & 0.8233 & 0.6451 & 0.0031 & 0.8690 \\
\hline & Max to Max & City & Yes & 0.7874 & 0.9937 & 0.1809 & 0.2449 \\
\hline & Max to Max & Province & No & 0.0923 & 0.4515 & 0.0000 & 0.0209 \\
\hline & Max to Max & Province & Yes & 0.2984 & 0.0261 & 0.0017 & 0.0000 \\
\hline & Max to Min & City & No & 0.8076 & 0.7940 & 0.1321 & 0.5015 \\
\hline & Max to Min & City & Yes & 0.7405 & 0.9266 & 0.3763 & 0.1696 \\
\hline & Max to Min & Province & No & 0.6159 & 0.8698 & 0.0029 & 0.2635 \\
\hline & Max to Min & Province & Yes & 0.8243 & 0.2689 & 0.0401 & 0.0000 \\
\hline \multirow[t]{12}{*}{ Financial asset holding } & Min to Min & City & No & 0.0000 & 0.0000 & 0.0000 & 0.0000 \\
\hline & Min to Min & City & Yes & 0.0000 & 0.0000 & 0.0000 & 0.0000 \\
\hline & Min to Min & Province & No & 0.0000 & 0.0000 & 0.0004 & 1.0000 \\
\hline & Min to Min & Province & Yes & 0.0008 & 0.0001 & 0.0061 & 0.0296 \\
\hline & Max to Max & City & No & 0.0000 & 0.0001 & 0.0000 & 0.0000 \\
\hline & Max to Max & City & Yes & 0.0007 & 0.0271 & 0.0001 & 0.0001 \\
\hline & Max to Max & Province & No & 0.0000 & 0.0000 & 0.0000 & 0.0000 \\
\hline & Max to Max & Province & Yes & 0.0000 & 0.0000 & 0.0000 & 0.0000 \\
\hline & Max to Min & City & No & 0.0000 & 0.0000 & 0.0000 & 0.0000 \\
\hline & Max to Min & City & Yes & 0.3976 & 0.7067 & 0.1458 & 0.0887 \\
\hline & Max to Min & Province & No & 0.7496 & 0.8993 & 0.0205 & 0.4355 \\
\hline & Max to Min & Province & Yes & 0.9532 & 0.6727 & 0.3390 & 0.0000 \\
\hline
\end{tabular}

Third, coverage breadth is probably the most important driver for the poverty reduction effect of digital finance. As shown in Tables 8 and 10, among all the Min to Min and Max to Max pairs regarding household income, the provincial intertemporal impact ( $\mathrm{Lag}=$ "Yes") of coverage breadth reaches 0.7543 (when $u q=0.90$ ) and 0.9475 (when $u q=0.95$ ) in the Min to Min dimension. We can infer from these results that coverage breadth may play an important role in the poverty reduction.

Fourth, digital finance development significantly promotes the fairness of household consumption, but its efficiency effect is not significant. According to results regarding household consumption in Tables 9 and 11, except for the non-lag pair with digitization level at the city-level, all Min to Min pairs are significant at 0.01 level. However, only the contemporaneous provincial pair is significant (at 0.10 level under 0.90 threshold and at 0.05 level under 0.95 threshold). These results indicate that the main effect of digital finance on household consumption is in inclusiveness and equity levels (corresponding to the Min to Min dimension) rather than the efficiency level (corresponding to the Max to Max dimension). This result 
Table 10 The TQCC estimation between digital finance indexes and household finance variables with $u q=0.95$

\begin{tabular}{|c|c|c|c|c|c|c|c|}
\hline & Pair & Scope & Lag & Index aggregate & Coverage breadth & Usage depth & Digitization level \\
\hline \multirow[t]{12}{*}{ Income } & Min to Min & City & No & 0.6081 & 0.7226 & 0.2239 & 0.2948 \\
\hline & Min to Min & City & Yes & 0.1895 & 0.0515 & 0.0358 & 0.0809 \\
\hline & Min to Min & Province & No & 0.9450 & 0.9703 & 0.7512 & 0.0248 \\
\hline & Min to Min & Province & Yes & 0.9955 & 0.9475 & 0.6329 & 0.5480 \\
\hline & Max to Max & City & No & 0.0230 & 0.0171 & 0.0494 & 0.0304 \\
\hline & Max to Max & City & Yes & 0.0210 & 0.0082 & 0.0296 & 0.0259 \\
\hline & Max to Max & Province & No & 0.2995 & 0.2055 & 0.5168 & 0.5314 \\
\hline & Max to Max & Province & Yes & 0.2237 & 0.6389 & 0.4389 & 0.7165 \\
\hline & Max to Min & City & No & 0.0008 & 0.0012 & 0.0196 & 0.0019 \\
\hline & Max to Min & City & Yes & 0.0020 & 0.0003 & 0.0079 & 0.0135 \\
\hline & Max to Min & Province & No & 0.0338 & 0.0133 & 0.2855 & 0.1138 \\
\hline & Max to Min & Province & Yes & 0.0248 & 0.4165 & 0.2461 & 0.6238 \\
\hline \multirow[t]{12}{*}{ Consumption } & Min to Min & City & No & 0.4059 & 0.4376 & 0.1070 & 0.1535 \\
\hline & Min to Min & City & Yes & 0.2168 & 0.0612 & 0.0438 & 0.0946 \\
\hline & Min to Min & Province & No & 0.5153 & 0.6060 & 0.2625 & 0.0000 \\
\hline & Min to Min & Province & Yes & 0.9955 & 0.9475 & 0.5427 & 0.5480 \\
\hline & Max to Max & City & No & 0.0021 & 0.0031 & 0.0208 & 0.0029 \\
\hline & Max to Max & City & Yes & 0.0034 & 0.0005 & 0.0117 & 0.0139 \\
\hline & Max to Max & Province & No & 0.0672 & 0.0376 & 0.2621 & 0.1140 \\
\hline & Max to Max & Province & Yes & 0.0732 & 0.1616 & 0.2524 & 0.5673 \\
\hline & Max to Min & City & No & 0.0031 & 0.0028 & 0.0137 & 0.0049 \\
\hline & Max to Min & City & Yes & 0.0058 & 0.0021 & 0.0124 & 0.0164 \\
\hline & Max to Min & Province & No & 0.0248 & 0.0128 & 0.1499 & 0.0489 \\
\hline & Max to Min & Province & Yes & 0.0247 & 0.1374 & 0.2461 & 0.5597 \\
\hline \multirow[t]{12}{*}{ Financial asset holding } & Min to Min & City & No & 0.6223 & 0.7306 & 0.3006 & 0.4165 \\
\hline & Min to Min & City & Yes & 0.2645 & 0.0974 & 0.0828 & 0.1333 \\
\hline & Min to Min & Province & No & 0.9187 & 0.9437 & 0.7340 & 0.0005 \\
\hline & Min to Min & Province & Yes & 0.8496 & 0.9475 & 0.9864 & 0.5480 \\
\hline & Max to Max & City & No & 0.0540 & 0.0396 & 0.1049 & 0.0649 \\
\hline & Max to Max & City & Yes & 0.0615 & 0.0260 & 0.0707 & 0.0557 \\
\hline & Max to Max & Province & No & 0.5619 & 0.3920 & 0.7569 & 0.6940 \\
\hline & Max to Max & Province & Yes & 0.5123 & 0.9235 & 0.8348 & 0.6535 \\
\hline & Max to Min & City & No & 0.0595 & 0.0431 & 0.1156 & 0.0715 \\
\hline & Max to Min & City & Yes & 0.0132 & 0.0050 & 0.0217 & 0.0206 \\
\hline & Max to Min & Province & No & 0.0332 & 0.0129 & 0.2851 & 0.1130 \\
\hline & Max to Min & Province & Yes & 0.0247 & 0.7976 & 0.2461 & 0.8898 \\
\hline
\end{tabular}

is in line with the purpose of digital inclusive finance and is consistent with $\mathrm{Li}$ et al. [20].

Fifth, it is interesting to note that there could be an "integration problem" from three sub-indexes of digital finance to the aggregate index. Tables 9 and 11 show that the intertemporal provincial TQCCs between consumption and all sub-indexes are significant at the 0.05 level, while that of index aggregate is insignificant. According to Tables 8 and 10, the intertemporal provincial TQCCs between consumption and coverage breadth, usage depth, and digitization levels are $0.1104,0.1731$, and 0.4948 when the threshold is 0.90 and are $0.1616,0.2524$, and 0.5673 when the threshold is 0.95 . The above seemingly contradictory empirical evidence may require further research in the future.

Besides, regarding the relationship between household consumption and the first dimension of digital finance index, coverage breadth, there are differences between their TQCCs and conventional linear correlation coefficients. Tables 9 and 11 show that the city-level 
Table $11 p$ values for TQCC between digital finance indexes and household finance variables with $u q=0.95$

\begin{tabular}{|c|c|c|c|c|c|c|c|}
\hline & Pair & Scope & Lag & Index aggregate & Coverage breadth & Usage depth & Digitization level \\
\hline \multirow[t]{12}{*}{ Income } & Min to Min & City & No & 0.0000 & 0.0000 & 0.0000 & 0.0000 \\
\hline & Min to Min & City & Yes & 0.0000 & 0.0000 & 0.0005 & 0.0000 \\
\hline & Min to Min & Province & No & 0.0000 & 0.0000 & 0.0000 & 0.4450 \\
\hline & Min to Min & Province & Yes & 0.0000 & 0.0000 & 0.0000 & 0.0000 \\
\hline & Max to Max & City & No & 0.0007 & 0.0061 & 0.0000 & 0.0000 \\
\hline & Max to Max & City & Yes & 0.0199 & 0.3341 & 0.0024 & 0.0061 \\
\hline & Max to Max & Province & No & 0.0000 & 0.0000 & 0.0000 & 0.0000 \\
\hline & Max to Max & Province & Yes & 0.0002 & 0.0000 & 0.0000 & 0.0000 \\
\hline & Max to Min & City & No & 0.9529 & 0.9127 & 0.0024 & 0.8056 \\
\hline & Max to Min & City & Yes & 0.8886 & 0.9972 & 0.3555 & 0.1103 \\
\hline & Max to Min & Province & No & 0.2806 & 0.7380 & 0.0000 & 0.0019 \\
\hline & Max to Min & Province & Yes & 0.6490 & 0.0000 & 0.0001 & 0.0000 \\
\hline \multirow[t]{12}{*}{ Consumption } & Min to Min & City & No & 0.0000 & 0.0000 & 0.0000 & 0.0000 \\
\hline & Min to Min & City & Yes & 0.0000 & 0.0000 & 0.0001 & 0.0000 \\
\hline & Min to Min & Province & No & 0.0000 & 0.0000 & 0.0000 & 1.0000 \\
\hline & Min to Min & Province & Yes & 0.0000 & 0.0000 & 0.0000 & 0.0000 \\
\hline & Max to Max & City & No & 0.7822 & 0.6203 & 0.0016 & 0.6619 \\
\hline & Max to Max & City & Yes & 0.7581 & 0.9908 & 0.1632 & 0.1018 \\
\hline & Max to Max & Province & No & 0.0390 & 0.2281 & 0.0000 & 0.0019 \\
\hline & Max to Max & Province & Yes & 0.1200 & 0.0000 & 0.0000 & 0.0000 \\
\hline & Max to Min & City & No & 0.6236 & 0.6659 & 0.0214 & 0.3933 \\
\hline & Max to Min & City & Yes & 0.5217 & 0.8820 & 0.1421 & 0.0582 \\
\hline & Max to Min & Province & No & 0.4443 & 0.7491 & 0.0000 & 0.1191 \\
\hline & Max to Min & Province & Yes & 0.6497 & 0.0000 & 0.0001 & 0.0000 \\
\hline \multirow[t]{12}{*}{ Financial asset holding } & Min to Min & City & No & 0.0000 & 0.0000 & 0.0000 & 0.0000 \\
\hline & Min to Min & City & Yes & 0.0000 & 0.0000 & 0.0000 & 0.0000 \\
\hline & Min to Min & Province & No & 0.0000 & 0.0000 & 0.0000 & 0.9993 \\
\hline & Min to Min & Province & Yes & 0.0000 & 0.0000 & 0.0000 & 0.0000 \\
\hline & Max to Max & City & No & 0.0000 & 0.0000 & 0.0000 & 0.0000 \\
\hline & Max to Max & City & Yes & 0.0000 & 0.0059 & 0.0000 & 0.0000 \\
\hline & Max to Max & Province & No & 0.0000 & 0.0000 & 0.0000 & 0.0000 \\
\hline & Max to Max & Province & Yes & 0.0000 & 0.0000 & 0.0000 & 0.0000 \\
\hline & Max to Min & City & No & 0.0000 & 0.0000 & 0.0000 & 0.0000 \\
\hline & Max to Min & City & Yes & 0.1190 & 0.5940 & 0.0167 & 0.0219 \\
\hline & Max to Min & Province & No & 0.2887 & 0.7486 & 0.0000 & 0.0020 \\
\hline & Max to Min & Province & Yes & 0.6493 & 0.0000 & 0.0001 & 0.0000 \\
\hline
\end{tabular}

contemporaneous and intertemporal effects and provincial level intertemporal effects for the Max to Max TQCC pairs are insignificant. However, intuitively there is a link between these indicators and household income and consumption, as those who earn more and spend more are more likely to embrace mobile payment services. This mechanism can be reflected in both the BET results and the linear correlation coefficients. In general, if there is a linear relationship between two random variables, BEStat has the power to detect the relationship as linear relationships are special cases of nonlinear relationships. ${ }^{4}$ According to BET results with sufficient depth (up to 2, 3 , and 4), the contemporary effects of coverage breadth in Max to Max pairs are all significant. Based upon the same dataset, the conventional Pearson's linear correlation coefficients can be calculated, which are 0.3737, 0.2969, and 0.5222 , respectively. Each of the Pearson's rho is

\footnotetext{
${ }^{4}$ On the other hand, TQCC is particularly developed for tail dependence. TQCC has been shown to asymptotically independent of sample correlation coefficients (statistics).
} 
significant at the 0.01 level. The above results mean that a financial mechanism may only work at the linear levels but not at the extreme levels. ${ }^{5}$

Sixth, financial asset holding is strongly tail dependent with digital finance aggregate and sub-indexes for all Min to Min and Max to Max pairs, which indicates that the digital finance development has positive effects on household financial asset holding in terms of both efficiency and fairness. This is in line with Radcliffe and Voorhies [26], which believes that digital financial services lubricate economic activities, make financial products and services cheaper, and increase the actual financial asset holdings of "poor" households. According to the $p$ values in Tables 9 and 11, most of the TQCCs between financial asset holding and digital finance (sub-)indexes are significant. In terms of the values of TQCCs, Min to Min pairs and Max to Max pairs show different patterns. For the former, the contemporaneous effect is greater than the intertemporal effect of the same scope $(0.5149>0.1933$ for city-level, $0.2660>0.1901$ for provincial level in Table 8; and $0.6223>0.2645$ for city-level, $0.9187>0.8496$ for provincial level in Table 10). For the latter, the effects from the provincial level are larger than that at the citylevel $(0.4494>0.0358$ for non-lag pairs, $0.3697>0.0344$ for lagging pairs in Table 8; and $0.5619>0.0540$ for nonlag pairs, $0.5123>0.0615$ for lagging pairs in Table 10). The above results indicate that digital finance and its three sub-aspects play important roles on household financial asset holdings in the same period and next period in terms of both efficiency and fairness.

Last but not least, the development of digital finance at the highest level will hardly harm fairness in terms of household consumption and income and generally has a very limited negative impact on the "worst" household in terms of financial asset holding. According to Tables 9 and 11, in the Max to Min dimension, except for the contemporaneous city-level pairs regarding financial asset holding, most of the TQCCs are insignificant, which means that the development of the "best" digital finance does not further harm the "worst" household income and consumption. As for household financial asset holding, even though the effect can be significant, the impact is limited because the effect only exists at a contemporaneous city-level and does not appear in a wider scope or an

\footnotetext{
5 We note that a bivariate normal random variable with Pearson's linear correlation coefficient $-1<\rho<1$ are (asymptotically) tail independent [25]. This can be easily verified via simulation experiments. Thus, as an applied extreme value theory research which is parallel with and adds to the existing literature, this study provides empirical evidence for the economic effects of digital finance from an extreme value perspective.
}

intertemporal situation. Based on the above results, we conclude that the evidence for "digital finance increases efficiency while harming fairness" is very weak.

In addition, it is interesting to explore a reverse question: Does the earlier household welfare enhance digital finance development? To answer this question, we examine the intertemporal TQCCs between household variables in the previous period and digital finance variables in the next period. The 0.95 level TQCCs results are reported in Appendix (TQCC values in Table 12, and $p$ values in Table 13). According to the results, one may notice that most pairs are insignificant, and none of the aggregate pairs is significant at the 0.01 level. In Table 13, only four aggregate pairs regarding income and one regarding consumption are significant at the 0.10 level. For financial asset holding, most pairs are insignificant except for two sub-index pairs (the city-level and provincial level Max to Max pairs for usage depth). Based on these findings, one can generally rule out the cases of "household economic activity is ahead of digital finance."

\section{Conclusions, policy implications, and future works}

\subsection{Conclusions}

This paper examines the roles of digital finance in three household economic variables: income, consumption, and financial asset holding. Three types of extreme pairs (Min to Min, Max to Max, and Max to Min) are conducted to correspond to the three economic connotations of digital finance: fairness, efficiency, and their trade-off. Meanwhile, each digital finance variable's economic externality and spatial spillover effect can also be investigated using the BMM method for variable construction. Based upon the panel data from PKU-DFIIC and CFPS from 2014 to 2018 and using the GEV-BETTQCC method, the contemporaneous and intertemporal tail dependences are eventually detected and quantified. The major results show that: (1) household income shows significant tail dependence with the aggregate and subindexes of digital finance in most of the cases of Min to Min pairs, which indicates that the poverty reduction effect of digital finance is huge; (2) digital finance has an incentive effect on household income growth and thus improves economic efficiency; (3) digital finance development significantly promotes the fairness of household consumption, but its efficiency effect is not significant; (4) the digital finance development has positive effects on household financial asset holding in terms of both efficiency and fairness; (5) digital finance 


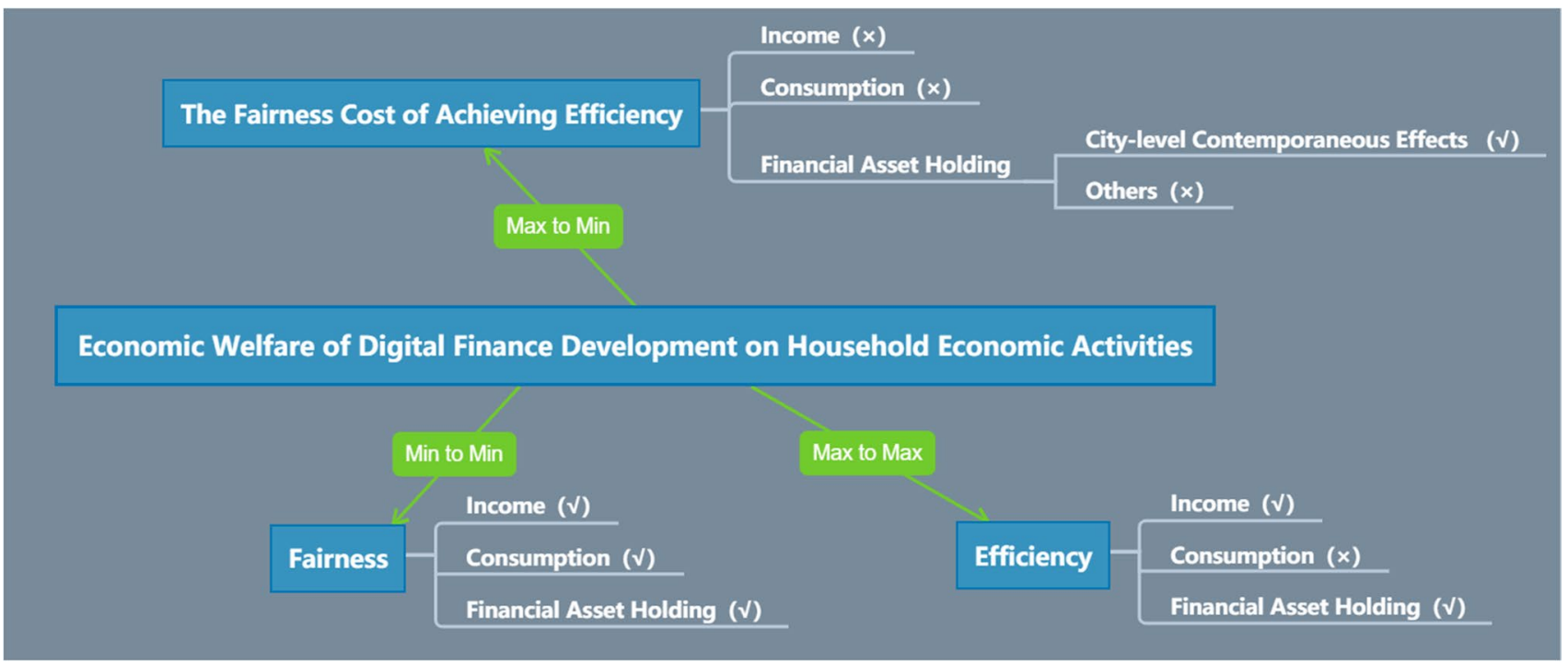

Fig. 1 The graphical representation of the tail dependences between digital finance development and household income, consumption, and financial asset holding

generally increases efficiency without harming fairness in terms of all cases of household income and consumption, and most of the cases regarding household financial asset holding; and (6) there is evidence that the positive spatial externality of digital finance exists. In addition, for pairs regarding household income and consumption, the wider the scope, the greater the spatial spillover effect.

The graphical representation of the above conclusion for each extreme pair is shown in Fig. 1, in which $(\sqrt{ })$ and $(X)$ stand for significant and insignificant, respectively.

Synthesizing the empirical evidence from three extreme pairs, three research questions raised in "Section 1" can be answered.

First, digital finance has significant fairness effects in reducing poverty, increasing consumption, and promoting financial asset holding. This is in line with the "inclusive" concept of digital finance.

Second, digital finance development shows effects of promoting incentives and efficiency in household income and financial asset holding, but this effect is relatively limited in household consumption.

Third, digital finance can generally increase efficiency (make the best digital finance level higher) without harming fairness (make the "worst" household worse). Even though the city-level contemporaneous effect for financial asset holding is significant, the impact is very limited.

Based on the above findings, we can summarize that "inclusiveness" is one of the characteristics of digital finance. From an economic welfare perspective, the "inclusiveness" can be demonstrated from the following three aspects.

First, "inclusiveness" is reflected in the fairness effect of digital finance. That is, from the Min to Min results, the "worst" parts of almost all household economic variables can be improved due to the improvement of the "lowest level" of digital financial conditions. This result strengthens the finding of Sarma and Pais [28], which shows that income is positively associated with the level of financial inclusion.

Second, "inclusiveness" is reflected in the intertemporal effect of digital finance. As seen from the empirical results, many lagging pairs show significant tail dependence, especially for the pairs regarding household income. These shreds of evidence inspire us to realize and highlight the persistency of the inclusive effect of digital finance.

Third, "inclusiveness" is reflected in the positive spatial externality of digital finance. As a byproduct, this paper shows that there are spatial spillover effects of digital finance toward household finance at both the city and provincial levels. The wider the scope, the greater the spatial spillover effect for pairs regarding household income and consumption.

\subsection{Implications}

The above three aspects of "inclusiveness" and our empirical findings imply several novel implications for policymakers. 
First, regarding the fairness effect of digital finance, the policymakers can best use this effect for poverty reduction and shrinking the household consumption gap. Poverty reduction and promotion of household consumption are both important macroeconomics and development economics issues and important policy formulation issues. Many traditional financial methods (such as private lending, credit cooperatives, and rural special insurance) have been discussed by economists or used by policymakers as important poverty reduction measures. The empirical findings in this paper not only show that digital finance can be used as a tool for poverty reduction like traditional financial methods but also evidence that digital finance also has a fairness effect on consumption and financial asset holding, which provides policymakers with more possibilities and options in realizing economic and social equity.

Second, regarding the intertemporal effect of digital finance, policymakers should consider "planning ahead" for digital financial resources and make full use of the lasting inclusive social benefits of digital finance construction. The fact that the effect of digital finance on household finance is intertemporal and persistent means that compared to many traditional macro-financial policies (such as deposit and loan interest rates and deposit reserve ratios), which is mainly used in reducing economic fluctuations, decreasing unemployment rate, and many other short-run issues regarding a business cycle, guiding digital finance industry is more of a policy instrument regarding long run issues such as economic growth and household welfare. Thus, formulating policies related to digital finance can be seen as a potential long-run investment to the whole economy and society for policymakers. This implication is in line with the expectation of Anand and Chhikara [3].

Third, regarding the positive spatial externality of digital finance, policymakers can utilize the spatial spillover effect of digital finance as an indirect instrument in regional economic policy formulation. From a regional coordination perspective, the existence of the spatial spillover effect of digital finance can make some seemingly unsolvable problems to be solved. In practice, there is often the "unbreakable" dilemma that: one region experiencing an economic downturn needs to increase the household income and consumption; however, due to historical or other reasons, it is not attractive enough for this area to achieve the agglomeration of capitalintensive enterprises or financial institutions. This makes it (seemingly) impossible for that region to increase the "worst" household income or consumption by introducing traditional financial channels (such as credit unions and bank lending to micro-enterprises). Comfortingly, a suggestion can be provided based on our empirical findings. The feasible solution is to arrange digital finance infrastructure (which is relatively not that costly) close to the target sub-region (for example, in the capital city or the largest city in a province) so that the "worst" household can benefit from the positive externality of digital finance. In practice, cloud payment and fin-techbased microfinance are good examples that make these relatively poor places eliminate the restrictions on the layout of traditional financial resources, thereby benefiting from the development of inclusive digital finance.

\subsection{Future study directions}

Based on our findings, there are further researches can be done in the future.

First, as mentioned in the fifth results of TQCC estimation (see "Section 4.3"), there is an "integration issue" between three sub-indexes and the aggregate index of digital finance, which needs to be further refined and investigated.

Second, this paper evidences the intertemporal effects of digital finance. It is interesting to further examine that how long does the intertemporal effect of digital finance exists? Moreover, does the intertemporal effect varies by area, time, or other situation? One can utilize (multivariate) time series analysis to further explore these questions.

Third, even though the spatial externality of digital finance can be outlined by using BMM, it is only a final skeleton. More evidence regarding the spatial spillover effects of digital finance can be provided using geography-based technologies, such as ArcGIS, GeoDa, and spatial econometric methods.

Last but not least, as shown in Tables 12, 13, and mentioned in "Section 4.3," the tail dependent relationship among variables can be different from that of linear dependence. In the future, it would be interesting to utilize the extreme value approaches and mainstream applied microeconomic methods simultaneously to detect economic causalities. In this sense, there are two possible directions for future studies. First, existing method(s) like the max-linear regression model [9] can be used for applied economic research. Second, for theoretical econometric study, many conventional econometric methodologies like causal inference and difference-indifferences (DID) can be extended to include extreme cases. 


\section{Appendix}

Table 12

Table 13

Table 12 The TQCC estimation for the lead effect of household economic variables against digital finance development $(u q=0.95)$

\begin{tabular}{lllllll}
\hline & & Scope & Index aggregate & Coverage breadth & Usage depth & Digitization level \\
\hline Income & Min to Min & City & 0.0191 & 0.0106 & 0.0167 & 0.0303 \\
& Min to Min & Province & 0.1111 & 0.1402 & 0.0946 & 0.0495 \\
& Max to Max & City & 0.0151 & 0.0066 & 0.0292 & 0.0267 \\
& Max to Max & Province & 0.0787 & 0.0823 & 0.1312 & 0.0755 \\
& Max to Min & City & 0.0002 & 0.0000 & 0.0007 & 0.0014 \\
& Max to Min & Province & 0.0010 & 0.0398 & 0.0065 & 0.0613 \\
Consumption & Min to Min & City & 0.0180 & 0.0057 & 0.0067 & 0.0090 \\
& Min to Min & Province & 0.0523 & 0.0596 & 0.0342 & 0.0300 \\
& Max to Max & City & 0.0102 & 0.0079 & 0.0212 & 0.0288 \\
& Max to Max & Province & 0.0305 & 0.0120 & 0.0388 & 0.0576 \\
& Max to Min & City & 0.0002 & 0.0001 & 0.0005 & 0.0036 \\
& Max to Min & Province & 0.0028 & 0.0083 & 0.0185 & 0.0514 \\
Min to Min & City & 0.0090 & 0.0024 & 0.0074 & 0.0049 \\
& Min to Min & Province & 0.0439 & 0.0500 & 0.0287 & 0.0162 \\
& Max to Max & City & 0.0065 & 0.0040 & 0.0148 & 0.0133 \\
& Max to Max & Province & 0.0447 & 0.0404 & 0.0849 & 0.0611 \\
& Max to Min & City & 0.0010 & 0.0002 & 0.0029 & 0.0010 \\
& Max to Min & Province & 0.0014 & 0.0091 & 0.0092 & 0.0518 \\
\end{tabular}

Table $13 p$ values of TQCC for the lead effect of household economic variables against digital finance development $(u q=0.95)$

\begin{tabular}{|c|c|c|c|c|c|c|}
\hline & & Scope & Index aggregate & Coverage breadth & Usage depth & Digitization level \\
\hline \multirow[t]{6}{*}{ Income } & Min to Min & City & 0.0315 & 0.2084 & 0.0546 & 0.0021 \\
\hline & Min to Min & Province & 0.0253 & 0.0072 & 0.0506 & 0.2924 \\
\hline & Max to Max & City & 0.0778 & 0.4504 & 0.0027 & 0.0051 \\
\hline & Max to Max & Province & 0.0964 & 0.0836 & 0.0107 & 0.1097 \\
\hline & Max to Min & City & 0.9988 & 0.9999 & 0.9823 & 0.9378 \\
\hline & Max to Min & Province & 0.9988 & 0.4087 & 0.9579 & 0.1894 \\
\hline \multirow[t]{6}{*}{ Consumption } & Min to Min & City & 0.0403 & 0.5336 & 0.4462 & 0.2894 \\
\hline & Min to Min & Province & 0.2648 & 0.2025 & 0.4906 & 0.5575 \\
\hline & Max to Max & City & 0.2232 & 0.3534 & 0.0190 & 0.0030 \\
\hline & Max to Max & Province & 0.5492 & 0.8788 & 0.4232 & 0.2178 \\
\hline & Max to Min & City & 0.9984 & 0.9995 & 0.9904 & 0.7352 \\
\hline & Max to Min & Province & 0.9910 & 0.9346 & 0.7626 & 0.2735 \\
\hline \multirow[t]{6}{*}{ Financial asset holding } & Min to Min & City & 0.2879 & 0.8539 & 0.3904 & 0.6032 \\
\hline & Min to Min & Province & 0.3557 & 0.2869 & 0.5797 & 0.8049 \\
\hline & Max to Max & City & 0.4609 & 0.6967 & 0.0844 & 0.1161 \\
\hline & Max to Max & Province & 0.3460 & 0.4010 & 0.0752 & 0.1911 \\
\hline & Max to Min & City & 0.9680 & 0.9987 & 0.8074 & 0.9704 \\
\hline & Max to Min & Province & 0.9977 & 0.9228 & 0.9212 & 0.2697 \\
\hline
\end{tabular}


Acknowledgements The authors thank the editor Dr. Yunchuan Sun and three anonymous reviewers' insightful comments, which help to improve the quality of the paper. Thanks are also due to Yan Guo (University of Glasgow) for his comments on the connotation of economic fairness.

Data availability The data utilized in this paper can be directly obtained from the Peking University Digital Financial Inclusion Index of China (PKU-DFIIC) and China Family Panel Studies (CFPS), or by contacting the authors.

\section{Declarations}

Conflict of interest The authors declare no competing interests.

\section{References}

1. Abbasi K, Alam A, Du MA, Huynh TLD (2021) FinTech, SME efficiency and national culture: evidence from OECD countries. Technol Forecast Soc Chang 163:120454

2. Alesina A, Angeletos GM (2005) Corruption, inequality, and fairness. J Monet Econ 52(7):1227-1244

3. Anand S, Chhikara KS (2013) A theoretical and quantitative analysis of financial inclusion and economic growth. Manag Labour Stud 38(1-2):103-133

4. Appiah-Otoo I, Song N (2021) The impact of fintech on poverty reduction: evidence from China. Sustainability 13(9):5225

5. Beck T, Pamuk H, Ramrattan R, Uras BR (2018) Payment instruments, finance and development. J Dev Econ 133:162-186

6. Bharadwaj P, Jack W, Suri T (2019) Fintech and household resilience to shocks: evidence from digital loans in Kenya (No. w25604). National Bureau of Economic Research

7. Chen L (2016) From fintech to finlife: the case of fintech development in China. China Econ J 9(3):225-239

8. Coles S, Bawa J, Trenner L, Dorazio P (2001) An introduction to statistical modeling of extreme values (Vol. 208. Springer, London, p 208

9. Cui Q, Xu Y, Zhang Z, Chan V (2021) Max-linear regression models with regularization. J Econ 222(1):579-600

10. Demir A, Pesqué-Cela V, Altunbas Y, Murinde V (2020) Fintech, financial inclusion and income inequality: a quantile regression approach. Eur J Financ 1-22

11. Fisher RA, Tippett LHC (1928) Limiting forms of the frequency distribution of the largest or smallest member of a sample. In Mathematical proceedings of the Cambridge philosophical society (Vol. 24, No. 2). Cambridge University Press, pp 180-190

12. Fleurbaey M, Maniquet F (2011) A theory of fairness and social welfare (Vol. 48). Cambridge University Press

13. Friedman M (1957) The permanent income hypothesis. In A theory of the consumption function. Princeton University Press, pp 20-37

14. Gnedenko B (1943) Sur la distribution limite du terme maximum d'une serie aleatoire. Ann Math 423-453

15. Gumbel EJ (1958) Statistics of extremes. Columbia University Press
16. Guo F, Wang J, Wang F, Kong T, Zhang X, Cheng Z (2019) Measuring China's digital financial inclusion: index compilation and spatial characteristics. Working paper, Institute of Digital Finance, Peking University

17. Huang S (2021) Digital finance development and household leverage in China: evidence from the CFPS. World Sci Res J 7(2):103-107

18. Kang X (2019) The impact of family social network on household consumption. Mod Econ 10(03):679

19. Kac M (1959) Statistical independence in probability, analysis and number theory, Volume 134. Mathematical Association of America

20. Li J, Wu Y, Xiao JJ (2020) The impact of digital finance on household consumption: evidence from China. Econ Model 86:317-326

21. Li M, Wu Q (2021) Research on the impact of digital inclusive finance on the income of urban vulnerable groups. Econ Manag 35(2):47-53 (In Chinese)

22. Liu T, Pan B, Yin Z (2020) Pandemic, mobile payment, and household consumption: micro-evidence from China. Emerg Mark Financ Trade 56(10):2378-2389

23. Moenninghoff SC, Wieandt A (2013) The future of peer-to-peer finance. Schmalenbachs Zeitschrift für betriebswirtschaftliche Forschung 65(5):466-487

24. Ozili PK (2018) Impact of digital finance on financial inclusion and stability. Borsa Istanbul Rev 18(4):329-340

25. Peng L (1999) Estimation of the coefficient of tail dependence in bivariate extremes. Statist Probab Lett 43(4):399-409

26. Radcliffe D, Voorhies R (2012) A digital pathway to financial inclusion. Available at SSRN 2186926

27. Rawls J (1958) Justice as fairness. Philos Rev 67(2):164-194

28. Sarma M, Pais J (2011) Financial inclusion and development. J Int Dev 23(5):613-628

29. Song Q, Li J, Wu Y, Yin Z (2020) Accessibility of financial services and household consumption in China: evidence from micro data. N Am J Econ Financ 53:101213

30. Yi X, Zhou Li (2018) Does digital financial inclusion significantly influence household consumption? Evidence from household survey data in China. J Financ Res 461(11):47-67 (In Chinese)

31. Zhao W (2019) Does health insurance promote people's consumption? New evidence from China. China Econ Rev 53:65-86

32. Zhang Z (2008) Quotient correlation: a sample based alternative to Pearson's correlation. Ann Stat 36(2):1007-1030

33. Zhang Z, Zhang C, Cui Q (2017) Random threshold driven tail dependence measures with application to precipitation data analysis. Stat Sin $685-709$

34. Zhang K (2019) BET on independence. J Am Stat Assoc 114(528):1620-1637

35. Zhang F, Zhang Z (2020) The tail dependence of the carbon markets: the implication of portfolio management. Plos One 15(8): 0238033

36. Zhang X, Zhang J, Wan G, Luo Z (2020) Fintech, growth and inequality: evidence from China's household survey data. Singapore Econ Rev 65(supp01):75-93

37. Zhou T, Chen M (2021) Digital penetration, inclusive finance and household wealth growth. J Financ Econ 47(5):1-16 (In Chinese)

Publisher's note Springer Nature remains neutral with regard to jurisdictional claims in published maps and institutional affiliations. 